\title{
ORAL CREATINE HYDROCHLORIDE SUPPLEMENTATION: ACUTE EFFECTS ON SUBMAXIMAL, INTERMITTENT BOUTS OF BENCH PRESS AND VERTICAL JUMP EXERCISES
}

by

Daniel McDonough

\author{
A thesis \\ submitted in partial fulfillment \\ of the requirements for the degree of \\ Master of Science in Kinesiology, Biophysical Studies \\ Boise State University
}

December 2017 
(C) 2017

Daniel McDonough

ALL RIGHTS RESERVED 


\section{BOISE STATE UNIVERSITY GRADUATE COLLEGE}

\section{DEFENSE COMMITTEE AND FINAL READING APPROVALS}

of the thesis submitted by

Daniel McDonough

Thesis Title: Oral Creatine Hydrochloride Supplementation: Acute Effects on Submaximal, Intermittent Bouts of Bench Press and Vertical Jump Exercises

Date of Final Oral Examination: $\quad 30$ October 2017

The following individuals read and discussed the thesis submitted by Daniel McDonough, and they evaluated his presentation and response to questions during the final oral examination. They found that the student passed the final oral examination.

Shawn R. Simonson, Ed.D Chair, Supervisory Committee

Yong Gao, Ph.D. Member, Supervisory Committee

Scott A. Conger, Ph.D. Member, Supervisory Committee

The final reading approval of the thesis was granted by Shawn R. Simonson, Ed.D, Chair of the Supervisory Committee. The thesis was approved by the Graduate College. 


\section{DEDICATION}

This is dedicated to my parents, Rebecca and David Holmes, and my uncle, Louie Medrano; wouldn't be here without you guys. And to my four brothers, Rich, Kamran, Jason, and J.D., who believed I could do this, but aren't here to see me finish it out. Rest in peace. 


\section{ACKNOWLEDGEMENTS}

A special thank you, Dr. Simonson, Dr. Gao, and Dr. Conger, for all of your hard work in editing and mentoring me through this process. Thank you NutraBio for supplying the creatine product for this study. Further, thank you to the Boise State University Biochemistry Department for working with me to analyze the creatine product for purity. Lastly, thank you to all who participated in this study and to those who assisted in any way. All of your efforts are greatly appreciated. 


\begin{abstract}
The purpose of this study was to examine the acute effects of oral creatine hydrochloride $(\mathrm{CrHCl})$ supplementation on three repeated bouts of bench press and vertical jumping exercises and body composition measures (body weight (BW), fat-free mass (FFM) and fat mass (FM)). Methods: Fifteen resistance trained males completed 3 sets of the barbell bench press (70\% 1RM) and 3 sets of the repeated counter-movement vertical jump (CMJ; 85\% maximal CMJ height), with 2 min rest between sets, before and after a $7 \mathrm{~d} \mathrm{CrHCl}$ intervention $\left(4 \mathrm{~g} \cdot \mathrm{day}^{-1}\right)$. A two-factor repeated measures ANOVA was used to determine significant main effects (time and set) with post-hoc Bonferroni analysis and interaction effects (time $\mathrm{x}$ set) for bench press and CMJ performances from pre- to post-intervention. A one-factor repeated measures ANOVA was used to assess pre- to post-intervention differences in body composition. Results: Significant main and interaction effects for time and set were found in the bench press from pre- to postintervention $(p<0.005$, for all) with Bonferroni analysis indicating increased performance on later sets (eg, Set $3>$ Set $2>$ Set $1, p<0.005$ ). Significant main effects for time and set were found in the CMJ test from pre- to post-intervention $(p<0.005)$ but no interaction effect was found $(p>0.05)$. Post hoc analysis indicated increased performance on later sets. BW was the only body measure to reach significance $(p<$ 0.005). Conclusion: Supplementation with $4 \mathrm{~g}$ of $\mathrm{CrHCl}$ for $7 \mathrm{~d}$ in healthy, resistance trained men significantly increased the number of repetitions performed during intermittent bouts of submaximal bench press and CMJ exercises and body weight.
\end{abstract}




\section{TABLE OF CONTENTS}

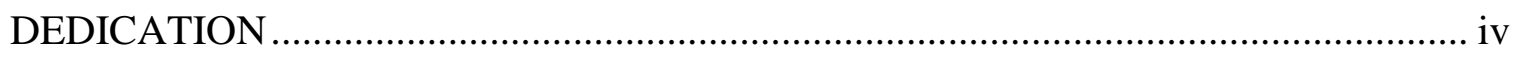

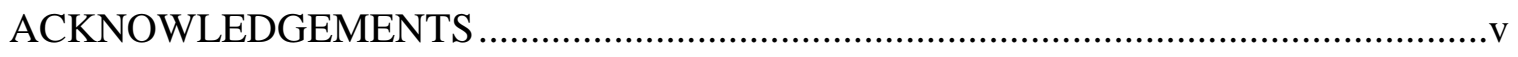

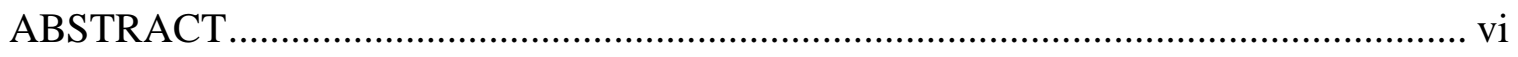

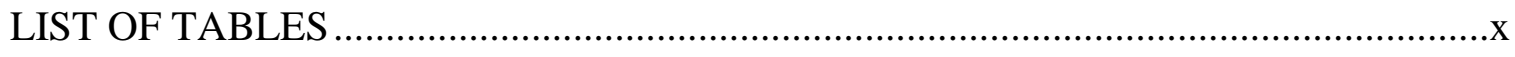

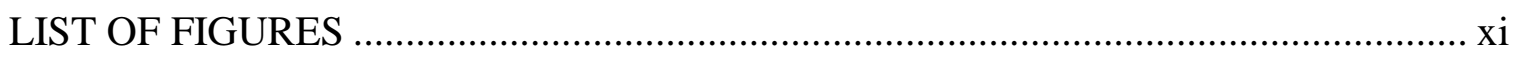

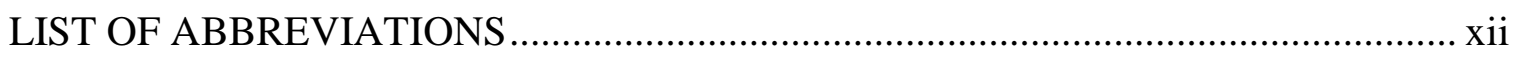

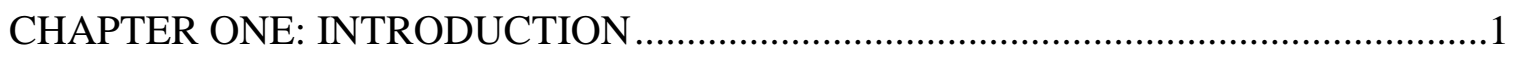

Physical Fitness and Physical Activity …………………………..............

Energy Transfer During PA ..................................................................

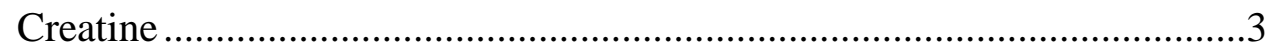

Creatine as a Supplement ....................................................................

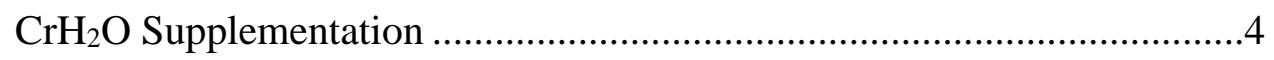

Body Mass and Lean Mass Effects of $\mathrm{CrH}_{2} \mathrm{O}$ Supplementation .................6

Issues and Non-Severe Adverse Effects with $\mathrm{CrH}_{2} \mathrm{O}$ Supplementation......6

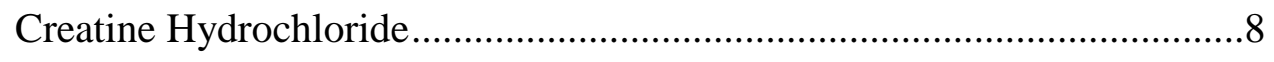

Enhanced Solubility and Intestinal-Uptake of $\mathrm{CrHCl}$...............................

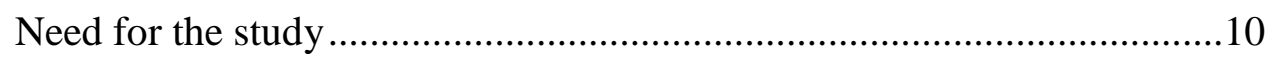

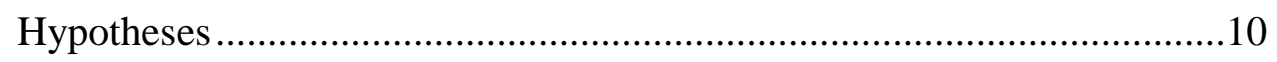

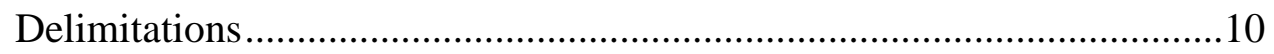




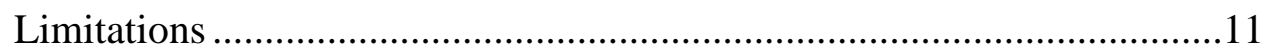

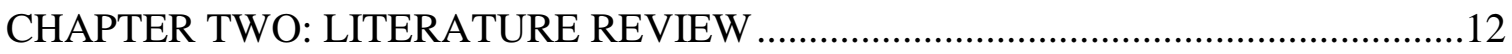

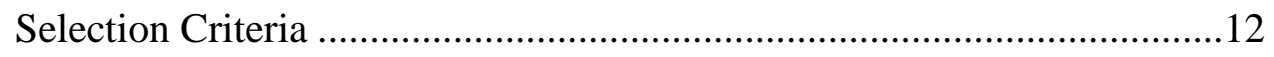

Review Format................................................................................12

Key Terms and Phrases ...........................................................................13

ATP-PCr Energy System ………………………………........................13

Creatine Supplementation: Ergogenic Benefits ..........................................18

Creatine Monohydrate: Uptake and Retention Assessed via Urinalysis ...25

Creatine Monohydrate: Adverse Effects....................................................30

Creatine HCl: Solubility and Intestinal Uptake …………..........................32

$\mathrm{CrHCl}$ and Resistance Training .................................................................

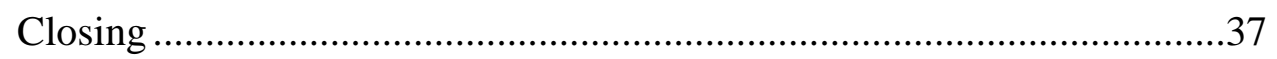

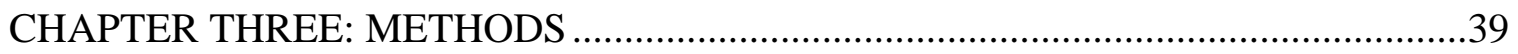

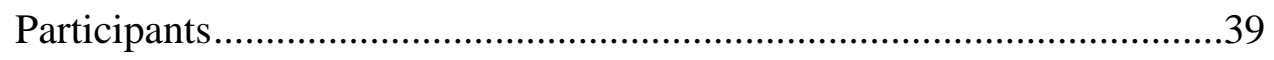

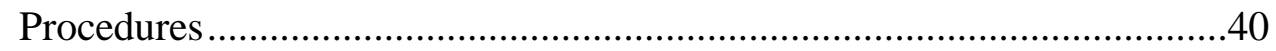

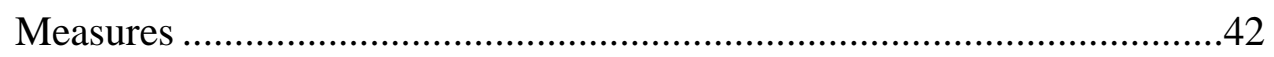

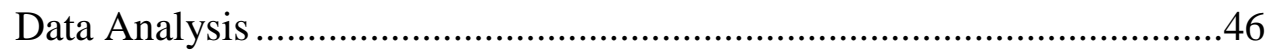

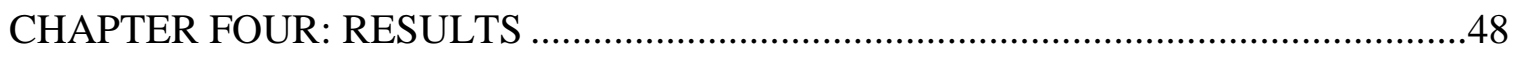

Dietary Supplement and Nutrition Intake .................................................48

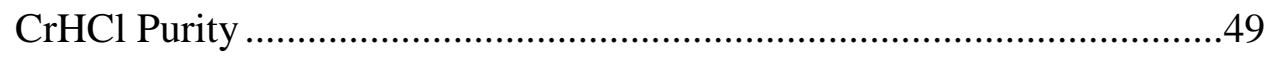

Repeated Bench Press ...............................................................................49

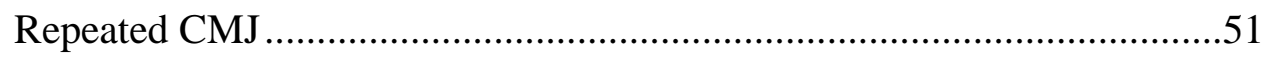

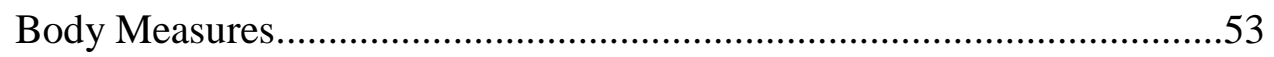




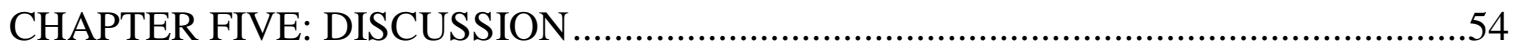

Limitations and Future Research ....................................................62

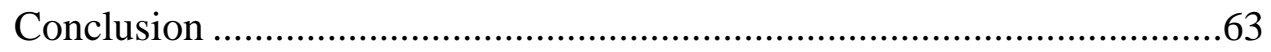

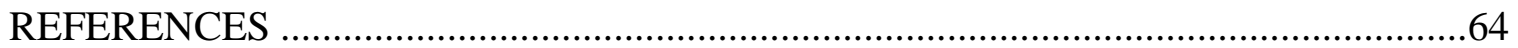

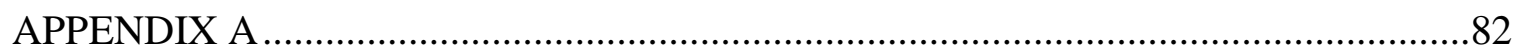

Informed Consent Form ....................................................................... 83

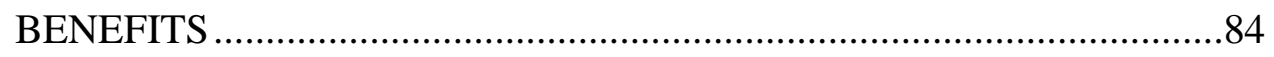

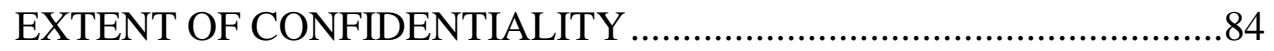

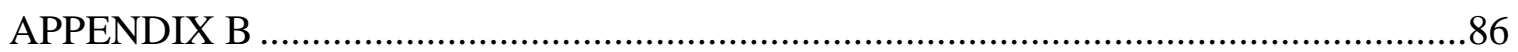

Physical Activity Readiness Questionnaire (PAR-Q)....................................86

APPENDIX C

Institutional Review Board Protocol................................................................91 


\section{LIST OF TABLES}

Table $3.1 \quad$ Study Protocol by Week …………………........................................ 42

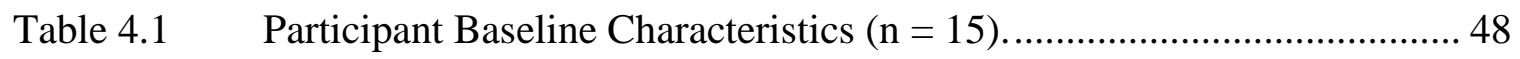

Table 4.2 Participant Repeated Bench Press Characteristics (repetitions)................ 51

Table 4.3 Participant Repeated CMJ Characteristics (repetitions)........................... 52

Table 4.4 Participant Body Composition Characteristics (kg)............................... 53 


\section{LIST OF FIGURES}

Figure 4.1 Effect for Time: Repeated Bench Press (Repetitions) ............................. 50

Figure 4.2 Effect for Time: Repeated CMJ (Repetitions) .................................... 52 


\section{LIST OF ABBREVIATIONS}

\begin{tabular}{|c|c|}
\hline BSU & Boise State University \\
\hline $\mathrm{Cr}$ & Creatine \\
\hline $\mathrm{CrHCl}$ & Creatine Hydrochloride \\
\hline $\mathrm{CrH}_{2} \mathrm{O}$ & Creatine Monohydrate \\
\hline ATP & Adenosine Triphosphate \\
\hline $\mathrm{PCr}$ & Phosphocreatine \\
\hline PF & Physical Fitness \\
\hline PA & Physical Activity \\
\hline $\mathrm{O}_{2}$ & Oxygen \\
\hline $\mathrm{H}_{2} \mathrm{O}$ & Water \\
\hline $\mathrm{CK}$ & Creatine Kinase \\
\hline $\mathrm{TCr}$ & Total Creatine \\
\hline $\mathrm{FCr}$ & Free Creatine \\
\hline ADP & Adenosine Diphosphate \\
\hline$P_{i}$ & Inorganic Phosphate \\
\hline $\mathrm{CHO}$ & Carbohydrate \\
\hline 1RM & One repetition Maximum \\
\hline g & Gram \\
\hline $\mathrm{kg}$ & Kilogram \\
\hline $\mathrm{Cl}$ & Centimeter \\
\hline
\end{tabular}




\section{CHAPTER ONE: INTRODUCTION}

\section{Physical Fitness and Physical Activity}

Physical fitness (PF) is a set of skill- or health-related attributes which may be evaluated through a variety of physical tests (eg, the mile-run test). ${ }^{1}$ One's level of PF is imperative to their health and overall quality of life, and according to the American College of Sports Medicine (ACSM), embodies five fundamental components: 1) cardiovascular endurance, 2) muscular endurance, 3) flexibility and mobility, 4) muscular strength, and 5) body-composition. ${ }^{2,3}$ A sixth component suggested by Clarke is muscular power. ${ }^{4}$ Physical activity (PA) is movement of the body produced by action of the muscle, causing an increase in energy expenditure and is critical to improving and maintaining PF. ${ }^{1}$ PA creates the greatest demand for the transfer of energy in the body. ${ }^{1}$ There are three distinct systems utilized to provide the energy, and the intensity and duration of a given physical task determines which predominates: 1) immediate-term adenosine triphosphate-phosphocreatine (ATP-PCr) system, 2) short-term glycolytic system, and 3) long-term aerobic system. ${ }^{5}$

\section{Energy Transfer During PA}

ATP is the body's energy currency because this energy-rich nucleotide-molecule provides power for all cells' energy-driven processes. ${ }^{6}$ Energy is released from ATP when it loses an inorganic phosphate $\left(\mathrm{P}_{\mathrm{i}}\right)$ molecule to form adenosine diphosphate (ADP). ${ }^{7}$ ATP is restored by adding back the $\mathrm{P}_{\mathrm{i}}$ to ADP. ${ }^{8}$ There is limited ATP storage to increase the sensitivity and responsiveness of energy supply. ${ }^{8} \mathrm{PCr}$ is stored as the energy 
reservoir because this high-energy, intracellular phosphate-compound undergoes anaerobic (without oxygen $\left(\mathrm{O}_{2}\right)$ ) splitting of one of its $\mathrm{P}_{\mathrm{i}}$ molecules for the rapid, shortterm re-synthesis of ATP. ${ }^{9}$ Both molecules maintain similar characteristics as a vast amount of free-energy $\left(\sim 7.3 \mathrm{kcal} \cdot \mathrm{mol}^{-1}\right)$ gets released when the $\mathrm{P}_{\mathrm{i}}$ is released in a reversible reaction. ${ }^{10}$ Creatine kinase $(\mathrm{CK}, \sim 5 \%$ on the outer membrane of the mitochondria, $\sim 4 \%$ on the sarcomere, $\sim 90 \%$ in the cytosol) catalyzes the near-equilibrium equation: $\mathrm{PCr}+\mathrm{ADP}+$ hydrogen $\left(\mathrm{H}^{+}\right) \leftrightarrow \mathrm{Cr}+\mathrm{ATP} .{ }^{10-12}$ Because PCr's CK-driven hydrolysis has a much greater free energy than that of ATP, it rapidly drives the phosphorylation of ADP to resynthesize ATP. ${ }^{11,13}$ During periods of all-out muscle contractions and a high demand for ATP, this process is driven to the right which reduces PCr concentration while simultaneously increasing free $\mathrm{Cr}(\mathrm{FCr})$ and $\mathrm{P}_{\mathrm{i}}$ ion concentrations and maintaining ATP concentration nearly unchanged. ${ }^{10,14}$ The process is reversed during recovery periods, as the free $\mathrm{Cr}$ and one $\mathrm{P}_{\mathrm{i}}$ ions bind, favoring $\mathrm{PCr}$ synthesis. ${ }^{10}$ This energy system is engaged at the initiation of PA and in all-out PA as skeletal muscle has the unique ability to rapidly increase its rate of energy consumption. Under conditions where explosive, maximal contractions are required, the millisecond increase in the turnover of energy can be up to 300-fold from resting to the fullyactivated state. ${ }^{10,15,16}$ Consequently, the availability of contributing sources to the ATP$\mathrm{PCr}$ energy system within the muscle cells, such as $\mathrm{Cr}$ concentration, become crucial as short-duration, near-maximal exercise proceeds and muscular fatigue begins to set in, requiring further ATP resynthesis. ${ }^{17} \mathrm{Cr}$ serves as a buffer to $\mathrm{H}^{+}$and $\mathrm{ADP}$ which accumulate in the muscle fibers as a product of ATP hydrolysis, lowering the $\mathrm{pH}$ and decreasing muscular performance. ${ }^{18}$ Given that skeletal muscle cells, especially type II, 
fast-twitch fibers, store approximately four-to six-times more PCr than ATP, it is advantageous to maintain high levels of intramuscular total $\mathrm{Cr}(\mathrm{TCr})$ content $(\mathrm{FCr}+\mathrm{PCr})$ for those who participate in short duration, maximal-effort exercise lasting 5-8 s, and up to $30 \mathrm{~s}$ for near-maximal PA. ${ }^{10,14,16,19-21}$ Because of the training protocols used, this applies too, to those who resistance train with the intent to increase muscular strength, muscular power, and improve fat-free mass (FFM; total amount of lean (non-fat) parts of one's body). ${ }^{22}$ However, the ability to resynthesize ATP via PCr hydrolysis declines approximately three-times faster than that of glycolysis (carbohydrate (CHO) catabolism). ${ }^{23,24}$ Thus, a greater quantity of $\mathrm{Cr}$ and $\mathrm{PCr}$ in skeletal muscle may translate to a greater quantity of ATP resynthesis via PCr hydrolysis and allow for more energy to be derived from high-energy phosphates before shifting to glycolytic pathways. $^{25}$ $\underline{\text { Creatine }}$

$\mathrm{Cr}$ is an organic, nitrogen-containing compound that is derived from the nonessential amino acids arginine, glycine, and methionine, that is, the body can manufacture creatine. ${ }^{26}$ Primarily the liver, but also the kidneys and pancreas, synthesize approximately $1 \mathrm{~g} \cdot \mathrm{day}^{-1}$ of $\mathrm{Cr}$, in addition to the approximately $1 \mathrm{~g} \cdot \mathrm{day}^{-1}$ obtained through the typical, non-vegetarian diet. ${ }^{26-28} 95 \%-98 \%$ of the body's $120-140 \mathrm{~g}$ of $\mathrm{Cr}$ is found in skeletal muscle, approximately $40 \%$ as $\mathrm{FCr}$ and the remaining $60 \%$ combined with $\mathrm{P}_{\mathrm{i}}$ to form PCr. ${ }^{12,29} \mathrm{FCr}$ undergoes nonenzymatic cyclization and approximately $1.6 \%$ of this TCr pool gets degraded to creatinine ( $\mathrm{Cn}$; sole byproduct of $\mathrm{Cr}$ metabolism) per day, and undergoes renal excretion. ${ }^{12,26,28-33}$ Therefore, a sedentary, $70 \mathrm{~kg}$ man who maintains a $120 \mathrm{~g}$ TCr pool, loses approximately $2 \mathrm{~g} \mathrm{Cr} \cdot \mathrm{day}^{-1}$ and TCr levels are maintained. However, Cn production and loss increases with PA levels. ${ }^{12,30}$ As the intensity and time 
of PA increases, individuals who wish to maintain maximal effort may seek alternative methods of maximizing intramuscular TCr levels. ${ }^{12,30}$ Thus, the exogenous supplementation of $\mathrm{Cr}$ is a common practice among those who resistance train as a means of maintaining elevated intramuscular TCr levels and enhancing total work output. ${ }^{12}$ $\underline{\text { Creatine as a Supplement }}$

The average daily intake of $\mathrm{Cr}$ is approximately $1 \mathrm{~g} \cdot \mathrm{day}^{-1}(0.2 \mathrm{~kg}$ of uncooked meat contains approximately $1 \mathrm{~g}$ of $\mathrm{Cr}$ ) and may be much lower for vegetarians who may consume minimal amounts of animal-food sources. ${ }^{12,29,34-37} \mathrm{Cr}$ content in meat (eg, beef and lamb) has been shown to decrease with cooking ( $90 \mathrm{~min}, 70^{\circ} \mathrm{C}$ ), as evidenced by an increase in Cn levels. ${ }^{38}$ Thus, exogenous ingestion of $\mathrm{Cr}$ through dietary supplements (commercially available products consumed in addition to one's usual diet) has long been practiced as an effective means for maintaining elevated intramuscular TCr levels. ${ }^{12,39}$ When ingested, Cr progresses through the intestinal mucosa of the digestive tract, arguably unaltered, where it then gets absorbed into the blood stream and ultimately, stored in skeletal muscle for the maintenance of energy homeostasis. ${ }^{40}$ Muscle TCr stores may be increased via supplementation and reach their typical limits $\left(150-155 \mathrm{mmol} \cdot \mathrm{kg}^{-1}\right.$ (dry muscle; DM)), resulting in excess Cr not being taken up by the muscle and voided in the urine. ${ }^{40}$

\section{$\underline{\mathrm{CrH}_{2} \mathrm{O} \text { Supplementation }}$}

One of the most researched and consumed form of $\mathrm{Cr}$ supplements is $\mathrm{Cr}$ monohydrate $\left(\mathrm{CrH}_{2} \mathrm{O}\right) .{ }^{41}$ Harris et al. were among the first to demonstrate that oral supplementation of 20-30 g. day ${ }^{-1}$ of $\mathrm{CrH}_{2} \mathrm{O}$ for several days could increase intramuscular TCr content between 30-50\%, with approximately $30 \%$ of the $\mathrm{Cr}$ being retained by the 
muscle in the first $2 \mathrm{~d} \cdot{ }^{42}$ The majority of studies that supplemented $\mathrm{Cr}$ at the recommended doses (eg, $4-5 \mathrm{~g} \cdot \mathrm{day}^{-1}, 10 \mathrm{~d}$ or $2-4 \mathrm{~g} \cdot$ day $^{-1}, 30 \mathrm{~d}$ ) reported performance enhancement on exercises where energy transfer is mostly from the phosphagen energy system, and the brief, between-bout rest periods are sufficient to restore intramuscular $\mathrm{PCr}$ in participants.

All-out PA with $\mathrm{CrH}_{2} \mathrm{O}$ supplementation is enhanced because the elevation in intramuscular TCr content allows for a prolonged use of PCr and replenishment of ATP, especially during intermittent exercise. ${ }^{23,43-48}$ Thus, better performances on maximaleffort tasks that go beyond relying solely on readily available ATP (eg, 1RM bench press) and rely on PCr hydrolysis to maintain maximal exertion. ${ }^{44-46}$ Moreover, because elevated intramuscular $\mathrm{PCr}$ may promote buffering of $\mathrm{H}^{+}$ions and ADP during maximal muscular contractions and reduce neuromuscular fatigue, this may allow for an increase in the number of muscular contractions possible during a given short-bout high intensity activity, such as resistance training. ${ }^{18,19,25,26,49-51}$ This ability for prolonged muscle contractions may ultimately lead to hypertrophy of the targeted skeletal muscle tissue and increased lean body mass due to the increased resistance training volume and elevated muscle protein synthesis..$^{23,47,52-55}$ Phillips and colleagues propose that because one of the most crucial stimuli for elevating skeletal muscle protein synthesis is muscle contraction, the greater number of contractions in a given training period may promote an elevated cumulative stimulus for protein synthesis and greater net muscle protein retention (skeletal muscle hypertrophy). ${ }^{52,56}$ 


\section{$\underline{\text { Body Mass and Lean Mass Effects of } \mathrm{CrH}_{2}} \underline{\mathrm{O} \text { Supplementation }}$}

Though most of the literature has found acute $\mathrm{CrH}_{2} \mathrm{O}$ interventions to positively influence body composition, few studies have found no or insignificant $(\sim 0.5 \mathrm{~kg})$ changes in FFM (healthy, older males) after $10 \mathrm{~d}$ of supplementing with $\mathrm{CrH}_{2} \mathrm{O}\left(20 \mathrm{~g} \cdot \mathrm{day}^{-1}\right)$. Further, men tend to accrue greater changes than women, likely due to their larger muscle mass. ${ }^{26,57-59}$ Independent of changes in hormonal (cortisol or testosterone) concentrations, $\mathrm{CrH}_{2} \mathrm{O}$ supplementation often results in increased body mass, ranging from $0.5-3 \mathrm{~kg}$ in periods between 1-3 wk. ${ }^{23,26,30,60-63}$ It remains unclear, however, the mechanism(s) by which this occurs, whether it be elevated intramuscular water retention, the direct anabolic effect of $\mathrm{Cr}$ on skeletal muscle tissue synthesis, or other indirect factors. ${ }^{64}$ It was further found that $\mathrm{CrH}_{2} \mathrm{O}$ supplementation, in addition to the resistance training protocol, promoted greater cross-sectional area of the muscle fibers: type I: $35 \%$ vs $11 \%$; type IIA: $36 \%$ vs $15 \%$; type IIAB: $35 \%$ vs $6 \%$, with vs. without supplementation, respectively. ${ }^{61}$ Participants in this study who were given the $\mathrm{CrH}_{2} \mathrm{O}$ treatment were able to train at higher volumes during wk 5-8, which suggests that increased quality in training sessions led to more favorable adaptations in their FFM and overall muscle morphologies. ${ }^{61}$ $\underline{\text { Issues and Non-Severe Adverse Effects with } \mathrm{CrH}_{2} \mathrm{O} \text { Supplementation }}$

It is important to note that chronic $\mathrm{Cr}$ supplementation lasting up to $4 \mathrm{y}$ has not yielded any serious adverse health effects and up to $5 \mathrm{y}$ had no effect on renal functioning among healthy athletes. ${ }^{65}$ Moreover, some anecdotes report hypertensive effects upon supplementing with $\mathrm{Cr}$, though acute $\left(5 \mathrm{~d}, 20 \mathrm{~g} \cdot \mathrm{day}^{-1}\right)$ and longer-duration $(6 \mathrm{wk}, 20$ $\mathrm{g} \cdot \mathrm{day}^{-1}(3 \mathrm{~d}), 10 \mathrm{~g} \cdot \mathrm{day}^{-1}$ maintenance) interventions have been shown to have no effects on blood pressure (systolic, diastolic, and mean). ${ }^{66,67}$ 
More commonly anecdotally reported non-severe adverse effects accompany $\mathrm{CrH}_{2} \mathrm{O}$ supplementation, such as subcutaneous water retention, gastrointestinal distress, nausea, and vomiting. These may be attributed to factors, such as co-ingestion with other nutrients (eg, large doses of $\mathrm{CHO}$ ), timing of ingestion (in the periworkout period), or a lack of ability for all of it to pass through the intestinal epithelial cells and make it into circulation. ${ }^{26,68,69} \mathrm{CrH}_{2} \mathrm{O}$ supplementation often accompanies weight gain, not just in FFM, however, but also by water retention in the muscle fiber and subcutaneous space. ${ }^{70,71}$ Moreover, supplementing with $\mathrm{CrH}_{2} \mathrm{O}$ has caused gastrointestinal distress, with reports of abdominal aches and cramps. ${ }^{26,72,73}$ There is a possible correlation between mega-doses of $\mathrm{CrH}_{2} \mathrm{O}$ in one serving, otherwise known as a "loading phase," where $10 \mathrm{~g}$ or more is ingested, and increased risk of diarrhea. ${ }^{74,75}$ This effect is likely due to the fact that $\mathrm{CrH}_{2} \mathrm{O}$ is poorly soluble in liquid and consequently, poorly absorbed by the intestines where the substance then sits and draws water in to the intestinal tract. ${ }^{26,69,72,74-76}$ Another study showed using an in-vitro model that a range of only 0.2$3 \%$ of ingested $\mathrm{CrH}_{2} \mathrm{O}$ was able to pass through the intestinal cells for upwards of a 90 min time period with the remainder being excreted by the body. ${ }^{77}$

A potential enhancement of $\mathrm{CrH}_{2} \mathrm{O}$ uptake is that of insulin augmenting $\mathrm{Cr}$ uptake by the skeletal muscles. ${ }^{25,40,64,78-81}$ Only approximately $50 \%$ of participants who supplemented with $\mathrm{CrH}_{2} \mathrm{O}$ alone, positively responded (significantly enhanced their intramuscular TCr), but 100\% positively responded with the presence of a large bolus of simple carbohydrates (CHO), such as dextrose. ${ }^{42,81,82}$ It takes approximately $95 \mathrm{~g}$ of simple $\mathrm{CHO}$ to provide a sufficient insulin spike to positively affect the intramuscular 
uptake of TCr upon supplementation with $\mathrm{CrH}_{2} \mathrm{O} \cdot{ }^{40,78-80}$ This insulin effect on $\mathrm{Cr}$ retention is likely due to insulin-stimulating, $\mathrm{Na}^{+}$-dependent, muscle-Cr transport. ${ }^{26,40,83,84}$ $\mathrm{Cr}$ retention in the body after supplementing can be tested via urinalysis, as $\mathrm{Cn}$ undergoes excretion by the kidneys, and increases gradually after the first few days as supplementation continues. ${ }^{12,26,28-33,85}$ Chanutin et al. reported that approximately $100 \%$ of ingested $\mathrm{Cr}$ passes through the intestines and makes it into the bloodstream, though most of the body's Cr retention takes place within the first couple of $d$ and approximately $90 \%$ of ingested $\mathrm{Cr}$ is excreted thereafter, with continued supplementation. ${ }^{85}$ Thus, as myocytes no longer maintain the capacity to extract circulating $\mathrm{Cr}$ from the blood after the first few days of supplementation (10-20 g. day $\left.{ }^{-1}\right)$, bodily retention will decline, and the excess will be excreted as $\mathrm{Cr}$ in the urine.$^{85}$ However, elevated $\mathrm{TCr}$ levels may be maintained if one continues to supplement with $\mathrm{Cr}$ while following a resistance training program, as trained skeletal muscle tissue better takes up circulating $\mathrm{Cr}$, especially as intramuscular $\mathrm{Cr}$ levels decrease from training and natural metabolic processes. ${ }^{42}$

Given the popularity of this dietary supplement and these potential adverse effects associated with it, manufacturers have attempted to produce different forms of $\mathrm{Cr}$ with the same performance benefits, minus the ill-effects of the monohydrate form. $\mathrm{Cr}$ hydrochloride $(\mathrm{CrHCl})$ was introduced to the market around 2009 as new form of $\mathrm{Cr}$ and is claimed to reduce the adverse effects of $\mathrm{CrH}_{2} \mathrm{O}$ while providing the same performance and FFM benefits as the $\mathrm{CrH}_{2} \mathrm{O}$ form. ${ }^{76}$

Creatine Hydrochloride

$\mathrm{CrHCl}$ is created using $\mathrm{CrH}_{2} \mathrm{O}$ and acetyl chloride $\left(\mathrm{CH}_{3} \mathrm{COCl}\right)$ as reactants with ethanol $\left(\mathrm{C}_{2} \mathrm{H}_{6} \mathrm{O}\right)$ as the solvent, which then produces a granular precipitate consisting of 
$\mathrm{CrHCl}$ salt, both in a high purity and yield ${ }^{76} \mathrm{CrHCl}$ products are typically much more expensive than $\mathrm{CrH}_{2} \mathrm{O}$ products (eg, NutraBio Creatine $\mathrm{HCl}, 135 \mathrm{~g}$, \$29.99: NutraBio Creatine Monohydrate Powder, 500g, \$14.99; NutraBio Labs, Middlesex, NJ). ${ }^{86}$

\section{Enhanced Solubility and Intestinal-Uptake of $\mathrm{CrHCl}$}

$\mathrm{CrHCl}$ was created as a form of $\mathrm{Cr}$ that yields higher aqueous solubility with the intention of being better mixed in liquid and better absorbed and retained with the same intended applications as $\mathrm{CrH}_{2} \mathrm{O} .{ }^{76}$ The $\mathrm{CrHCl}$ patent reported the aqueous solubility of $\mathrm{CrHCl}$ to be in excess of approximately $150 \mathrm{mg} \cdot \mathrm{mL}^{-1}$, while that of $\mathrm{CrH}_{2} \mathrm{O}$ and $\mathrm{Cr}$ citrate salt was only approximately $10-15 \mathrm{mg} \cdot \mathrm{mL}^{-1} \cdot{ }^{76}$ Subsequent research has confirmed their claims, finding $\mathrm{CrHCl}$ to be 38 -times more soluble in solution than its $\mathrm{CrH}_{2} \mathrm{O}$ counterpart. ${ }^{87}$ Following, Gufford and colleagues reported that when Cr ethyl ester was placed in a highly acidic state $(\mathrm{HCl})$, with the $\mathrm{pH}$ stabilized at $\mathrm{pH} 1.0$, the amount of $\mathrm{Cr}$ absorbed by the intestines consequently increased $60 \%$, due to the enhanced solubility and greater permeability characteristics under these acidic conditions, in comparison to $\mathrm{CrH}_{2} \mathrm{O}$, which is more basic in nature. ${ }^{69}$ Gufford et al. propose that because the added $\mathrm{HCl}$ group is highly stable at the $\mathrm{pH}$ level of the gastrointestinal tract, its greater permeability and absorption are superior to that of $\mathrm{Cr}$, alone. ${ }^{69}$ This contradicts the aforesaid findings in the Chanutin et al. study, as it was found that nearly all of the $\mathrm{Cr}$ ingested passed through the intestines and made it into circulation. ${ }^{85}$ Nevertheless, the implication is that $\mathrm{CrHCl}$ can be supplemented at a much smaller dose than $\mathrm{CrH}_{2} \mathrm{O}$, while still producing similar performance benefits with a reduced potential for the reported side effects. Therefore, with greater solubility in liquid, more efficient absorption by the intestines, and a smaller required dose than $\mathrm{CrH}_{2} \mathrm{O}, \mathrm{CrHCl}$ may minimize the stomach 
and water retention issues reported by those who supplement with $\mathrm{CrH}_{2} \mathrm{O}$. However, a study examining the body's retention of $\mathrm{Cr}$ upon supplementing with $\mathrm{CrHCl}$ would be needed to tell whether these retention-effects are truly prevalent; currently, no such literature exists.

Need for the study

The study at hand will be among the first to investigate the acute resistance training responses after $7 \mathrm{~d}$ of supplementing with $\mathrm{CrHCl}$. This study will bring value to the literature as it will add to the sparse literature pertaining to $\mathrm{CrHCl}$ as a dietary supplement and will provide data that can be compared with previous findings in regards to $\mathrm{CrH}_{2} \mathrm{O}$ 's ability to acutely affect submaximal, intermittent exercise

performances. ${ }^{23,40,42,78}$ These findings will allow for researchers and consumers to decide which form of $\mathrm{Cr}$ is superior for consumption based on dosing requirements and performance benefits.

Hypotheses

It was hypothesized that:

1) $4 \mathrm{~g}$ of $\mathrm{CrHCl} \cdot \mathrm{day}^{-1}$ for $7 \mathrm{~d}$ will significantly increase repetitions completed on three sets of the repeated barbell bench press and CMJ exercises at $70 \%$ of participants' 1RMs.

2) $4 \mathrm{~g}$ of $\mathrm{CrHCl} \cdot \mathrm{day}^{-1}$ for $7 \mathrm{~d}$ will significantly increase BW, FFM and decrease FM. $\underline{\text { Delimitations }}$

The study at hand will require participants to be currently resistance trained (minimum of $3 \mathrm{~d} \cdot \mathrm{wk}^{-1}$ ) with a minimum of $1 \mathrm{y}$ experience. Moreover, participants will be 
between the ages of 18 and $34 \mathrm{y}$, will not use anabolic steroids, be vegans or vegetarian, and/or must cease the use of their current nutritional supplement regimens.

\section{$\underline{\text { Limitations }}$}

Limitations of the current study include untested participants who are:

- Untrained and low-trained.

- Youth, not 18 y of age and adults and elderly, greater than 34 y of age.

- Anabolic steroid users.

- Vegans and vegetarians.

- Diabetics.

- Unwilling to stop taking dietary supplements. 


\section{CHAPTER TWO: LITERATURE REVIEW}

\section{$\underline{\text { Selection Criteria }}$}

Selection criteria for this review gave preference to studies investigating $\mathrm{CrH}_{2} \mathrm{O}$ 's retention, and training studies pertaining to both $\mathrm{CrHCl}$ and $\mathrm{CrH}_{2} \mathrm{O}$ whose participants were: 1) non-vegetarian or vegan, 2) male and female, 3) currently well trained (minimum 1 y of current and consistent resistance training experience), 4) non-steroid users, 5) not taking any other supplements at the time of the respective study, and 6) nondiabetics. Studies investigating the retention of $\mathrm{TCr}$ after supplementing with $\mathrm{CrH}_{2} \mathrm{O}$ will be restricted to 1992, and beyond, as this was the year of the seminal study by Harris et al. that first investigated this. ${ }^{42}$ Any study examining $\mathrm{CrHCl}$ supplementation will be restricted to 2009 and beyond, as this was when it was first brought to the market for commercial use. ${ }^{42,76}$ No such literature exists relative to TCr pool enhancement and retention upon supplementing with $\mathrm{CrHCl}$ and thus, will be disregarded from this review. Studies detailing the intramuscular ATP-PCr energy system and/or skeletal muscle structure and function will have no date restrictions.

\section{$\underline{\text { Review Format }}$}

The review starts with a brief section detailing the ATP-PCr energy system. Following is a section reviewing $\mathrm{CrH}_{2} \mathrm{O}$ retention studies. Subsequent is a section reviewing the ergogenic benefits of $\mathrm{Cr}$ supplementation across different forms of PA, followed by a section reviewing anecdotal adverse effects associated with $\mathrm{CrH}_{2} \mathrm{O}$ 
supplementation. Following will be a section on $\mathrm{CrHCl}$ and any literature available pertaining to it, which currently is very limited.

\section{$\underline{\text { Key Terms and Phrases }}$}

Key terms and phrases used in this search were "ATP-PCr," "anaerobic energy," “anaerobic metabolism," “creatine," “creatine monohydrate," “creatine hydrochloride," "creatine $\mathrm{HCl}$," "creatine retention, "creatine carbohydrate," "creatine insulin," "creatine solubility," "muscle fiber," and "type II muscle fiber."

Search engines utilized for this search included Web of Science, Google Scholar, Medline, PubMed, Boise State University Albertson Library Worldcat, Science Direct, and ASC Publications.

\section{ATP-PCr Energy System}

\section{Enzymes: The Biologic Catalysts}

Enzymes are large protein catalysts that are highly specific in function, catalyzing the forwards and backwards rates of chemical reactions without being altered or consumed during the respective reactions. ${ }^{34}$ They reduce the required activation energy (initial energy to start a reaction), changing the rate of the reaction without changing equilibrium constants and free energy. ${ }^{34}$ Their globular, three-dimensional protein structure determines the interaction with a specific substrate. ${ }^{22}$ This interaction takes place, described as a "lock-and-key mechanism" or "induced fit," when the active site on the outer surface of the protein interlocks perfectly with the active site of the respective substrate. ${ }^{34,88,89}$ Subsequent to the formation of the enzyme-substrate complex, a new product with the new bonds is created after the initial splitting of the chemical bond. ${ }^{34}$ 
For all-out PA, associated energy system enzyme activity increases to about 100-times their resting level, especially during each step of the hydrolysis process. ${ }^{22}$

\section{$\underline{\text { Hydrolysis Reactions }}$}

The hydrolysis, or "water splitting," process catabolizes complex, organic molecules, with the splitting of chemical bonds initiating the decomposition process by adding the components of water $\left(\mathrm{H}_{2} \mathrm{O}\right.$; hydrogen atom $\left(\mathrm{H}^{+}\right)$and a hydroxyl group $\left.\left(\mathrm{OH}^{-}\right)\right)$ to the byproducts of the reaction, as shown in the basic hydrolysis reaction equation: (AB $+\mathrm{HOH} \rightarrow \mathrm{A}-\mathrm{H}+\mathrm{B}-\mathrm{OH}) .{ }^{90}$ Each step of the decomposition process is accelerated by specific enzymes. ${ }^{91}$ During maximal-effort PA, the enzyme-mediated hydrolysis of both PCr and ATP are critical for maintaining adequate ATP levels and overall intramuscular energy homeostasis. ${ }^{40}$

\section{ATP: The Energy Currency}

ATP is a naturally occurring nucleotide that is found in every cell of the human body. ${ }^{8}$ Approximately $10 \%$ more ATP is found in type II muscle fibers than in oxidative, type I fibers (eg, the vastus lateralis versus the soleus muscle).${ }^{92}$ Its base is purine (adenine) and ribose (adenosine) and is linked to three negatively-charged $\mathrm{P}_{\mathrm{i}}$ groups. ${ }^{8,90}$ The fact that these negatively charged $\mathrm{P}_{\mathrm{i}}$ groups are so closely packed and repel each other makes ATP highly unstable. ${ }^{8,90}$ Chemically speaking, the triphosphate tail is similar to a tightly-bounded spring that is ready to uncoil with great energy. ${ }^{8,90}$ Thus, ATP is the ideal agent of energy-transfer, as it stores potential energy from ingested food molecules within its phosphate bonds and readily transfers this energy to other low-energy compounds to raise them to a greater activation level. ${ }^{90}$ 
When ATP undergoes hydrolysis and its terminal, energy-packed $\mathrm{P}_{\mathrm{i}}$ group is anaerobically cleaved off, the chemical "spring" becomes relaxed, making the entire molecule more stable. ${ }^{90}$ Upon the release of this $\mathrm{P}_{\mathrm{i}}$ from ATP, an abundance of free energy gets released $\left(\sim 7.3 \mathrm{kcal} \cdot \mathrm{mol}^{-1}\right), A T P=H_{2} O \stackrel{\text { ATPase }}{\longrightarrow} A D P+P_{i}+7.3 \mathrm{kcal}^{34,93}$ This energy from the hydrolysis of ATP (mediated by the ATPase enzyme) powers all bodily functions, such as nerve transmission, tissue synthesis, and muscular action. ${ }^{13}$ In muscle cells, molecular motors are powered and muscle shortening is energized thanks to this release of free energy. ${ }^{60} \mathrm{ADP}$ is then anaerobically converted back to ATP primarily in the muscle cells' cytosol, as PCr undergoes hydrolysis in order to maintain a continuous supply of ATP.$^{22}$ Hence, $\mathrm{PCr}$, an energy reservoir, is a critical component of the phosphate energy system.

\section{PCr: The Energy Reservoir}

ATP's storage is limited due to its heavy weight and to increase sensitivity of the energy production response. ${ }^{29}$ This makes maximal-effort PA possible for only a few muscle-twitches, or 4-10 s, if relying primarily on ATP as an energy source. ${ }^{3,7}$ To maintain energy homeostasis and keep intramuscular levels of ATP stable (at approximately resting levels), $\mathrm{PCr}$ is hydrolyzed and phosphorylates the direct byproduct of ATP hydrolysis, ADP, within a fraction of a second to resynthesize ATP. ${ }^{28,78,90,94}$ Phosphocreatine, also referred to as creatine phosphate, is a phosphorylated $\mathrm{Cr}$ molecule $\left(\mathrm{Cr}+\mathrm{P}_{\mathrm{i}}\right) .{ }^{3,7}$ The enzyme-mediated $(\mathrm{CK})$ hydrolysis of $\mathrm{PCr}$ yields a much higher free energy $\left(10.3 \mathrm{kcal} \mathrm{mol}^{-1}\right)$ than the ATPase-mediated hydrolysis of ATP, which is enough energy to power the phosphorylation of ADP to ATP. ${ }^{3} \mathrm{PCr}$, thereby, serves as the highenergy P-bond reservoir. ${ }^{3}$ 


\section{Immediate Energy via the ATP-PCr Energy System}

During maximal exercise, the rate of ATP turnover in skeletal muscle may increase several hundredfold. ${ }^{17}$ Despite this vast increase in ATP turnover, intramuscular ATP content remains relatively unchanged. ${ }^{17,34}$ This ATP hydrolysis/resynthesis balance is possible because ATP is resynthesized via $\mathrm{PCr} .{ }^{17}$ The ATP-PCr energy system maintains four significant roles within skeletal muscle: 1) temporally buffers muscle ATP (to maintain ATP stores), 2) spatially buffers ATP (decrease cellular gradients of both ATP and ADP), 3) controls the oxidative phosphorylation process, and 4) acts as the primary buffer of $\mathrm{H}^{+}$in the skeletal muscle cell. ${ }^{17}$

Muscular fatigue has been associated with decreased PCr levels and intramuscular $\mathrm{pH}$, resulting in the inability to continue muscular contractions. ${ }^{6,95-98}$ Muscular energy deficiency may not be the product of ATP shortage but may rather be due to increases in ADP and $\mathrm{P}_{\mathrm{i}}$ (products of ATP hydrolysis), as it has been shown that muscle force, velocity, shortening, and rate of relaxation may be impaired by the increased presence of both ADP and $\mathrm{P}_{\mathrm{i}} \cdot{ }^{17}$ This suggests that muscular fatigue is more so a result of product inhibition than a lack of substrate availability ${ }^{17}$ Increasing available intramuscular substrates through $\mathrm{Cr}$ supplementation has been shown to delay muscular fatigue and increase muscular performance by better utilizing the ADP and $\mathrm{P}_{\mathrm{i}}$ for resynthesis of the high energy phosphates. ${ }^{26}$

As ATP is used, the increase in byproducts of the high-energy phosphate hydrolysis, adenosine monophosphate (AMP; result of ATP utilization exceeding ATP regeneration) and $\mathrm{P}_{\mathrm{i}}$, initiate the breakdown of glucose through glycolysis without the need for $\mathrm{O}_{2}{ }^{14,17,20,99,100}$ Glycolysis breaks down the six-carbon glucose into two three- 
carbon pyruvates as well as liberating electrons and $\mathrm{H}^{+} .{ }^{14}$ Pyruvate can either continue to be broken down via the Kreb's cycle if $\mathrm{O}_{2}$ is present or, if energy demand is high, be cleared by forming lactate. ${ }^{14}$ Ensuing PCr degradation, anaerobic glycolysis predominates and provides approximately $70 \%$ of the entire energy demand for nearmaximal PA lasting approximately 30-180 s. ${ }^{14,16,20,99}$ Anaerobic glycolysis (lactate endproduct) is a rapid process that yields only limited amounts of ATP. ${ }^{101}$ Considerable amounts of lactate can accumulate in the blood and increase more than 30-fold above resting levels during maximal movements utilizing large muscle groups. ${ }^{14,16,20,99}$ One's muscular endurance heavily relies on this energy system and has implications for PA, such as maximal sprints and resistance training that lasts for approximately $30 \mathrm{~s} .{ }^{14,16,20,99}$ Further, this applies for activities lasting slightly longer, such as during the last few hundred yards of a mile run or maximal effort on a $440 \mathrm{~m}$ run or $100 \mathrm{~m} \mathrm{swim.}^{22}$

When the pyruvate end-product of glycolysis enters the Kreb's cycle, it is a slow process that requires $\mathrm{O}_{2}$ and yields substantial amounts of ATP to provide almost all the necessary energy for PA lasting for several minutes and beyond. ${ }^{102,103}$ Taking the pyruvate formed in glycolysis, the Kreb's cycle transfers electrons and $\mathrm{H}^{+}$atoms to the electron transport chain (ETC). ${ }^{103}$ It is within the ETC that aerobic metabolism relies on $\mathrm{O}_{2}$, as it is the final electron acceptor within the respiratory chain, where it bonds with $\mathrm{H}^{+}$ to form water $\left(\mathrm{H}_{2} \mathrm{O}\right)$ as ATP is formed. ${ }^{103}$ Energy substrate availability determines one's cardiovascular endurance and the ability of the aerobic system to replenish ATP, which has implications for endurance activities, such as long-distance walking, jogging, running, and swimming. ${ }^{22}$ The amount of ATP turnover during aerobic activities is very 
high, yet this is a slow process when compared to fast glycolysis and the phosphagen system. ${ }^{17}$

Creatine Supplementation: Ergogenic Benefits

$\mathrm{Cr}$ is purchased over-the-counter as a dietary supplement and comes in numerous forms: powder, capsules, tablets, and stabilized liquid, though purity is not guaranteed as dietary supplements are unregulated by the Food and Drug Administration. ${ }^{26,104,105}$ In 1994, a regulatory framework pertaining to dietary supplements in the United States was established by the Dietary Supplement Health and Education Act (DSHEA, 1994), which eliminated regulation of the supplement industry. Consequently, sales of dietary supplements in the US increased from $\$ 4$ billion (1994) to $\$ 35$ billion (2015), more than an eight-fold increase over a 21 y time span. ${ }^{39,104-107}$ Around the year 2000, alone, an estimated 2.5-thousand metric tons of $\mathrm{Cr}$ was consumed, which coincides with 2001 sales of Cr supplements ( $\$ 400$ million), and one can assume that as US dietary supplement sales have continued to increase over time, $\mathrm{Cr}$ sales have, too. ${ }^{26,41}$ More than $48 \%$ of male collegiate athletes use, or have used $\mathrm{Cr}$ as a supplement in preparation for their respective competitions; such numbers for females in this population have not been reported. ${ }^{41}$ Among strength and power athletes (eg, Olympic lifters, powerlifters, strongman competitors, and recreational weightlifters), the prevalence of $\mathrm{Cr}$ is much greater, exceeding $80 \% .{ }^{41}$ Further, upwards of $71 \%$ of youth and adolescent athletes report using dietary supplements, and $90 \%$ of those in high school who reported using dietary supplements reported supplementing with $\mathrm{Cr}^{41,108}$

$\mathrm{CrH}_{2} \mathrm{O}$ supplementation during training has been found to enhance performances in running (improved final, total, and best times for 300 and 1,000 $\mathrm{m}$ and $4 \times 1,000 \mathrm{~m}$ 
runs), cycle ergometry (better maintenance of pedal frequency at 4-6 s (all three bouts) and at the end of a $10 \mathrm{~s}$ bout, and increased peak-power, mean power, and total work on bouts 1 and 2), bench press (increased 1RM and amount of repetitions completed at 70\%repetition maximum), isokinetic unilateral knee-extension (greater peak-torque production on bouts 2, 3, and 4), and the jump squat (increased peak-power production on all five trials), to list a few..$^{23,43-48}$

A myriad of studies, though not all, show that $\mathrm{Cr}$ supplementation can significantly enhance healthy young adults' abilities to produce greater muscular force and/or power output for maximal, short-duration exercise, especially those with brief intervals of rest between exercise bouts, and less so for enhancing single-effort performances (eg, $1 \mathrm{RM}$ testing). ${ }^{26}$ Participants in these studies vary in athletic ability, ranging from untrained to high-level collegiate athletes, and the improved activities include short-duration, maximal cycling, repeated jumping, sprinting, swimming, and resistance training, to list a few. ${ }^{26}$

Acute $\mathrm{Cr}$ supplementation has been found to enhance resistance training in multiple instances. ${ }^{23,47}$ In one study, Volek et al. split fourteen resistance trained men into two groups (placebo (Pl)) or Cr group), and both groups executed a jump squat protocol ( 5 sets, 10 repetitions, $30 \%$ of participants' $1 \mathrm{RM}$ ) and a bench press protocol ( 5 sets, failure, 10-repetition maximum). This took place on three occasions, each trial separated by $6 \mathrm{~d}$ while discontinuing resistance training. Prior to trial 1 , neither group was supplemented, from trial 1 to trial 2 both groups ingested the Pl treatment, and between trial 2 and trial 3, the $\mathrm{Cr}$ group consumed $25 \mathrm{~g} \mathrm{CrH} \mathrm{O}_{2} \mathrm{O} \mathrm{d}^{-1}$ while the $\mathrm{Pl}$ group consumed the same amount of the Pl treatment. The Pl group exhibited no significant increases in 
bench press repetitions completed from trial 2 to trial 3, while the Cr group saw significant increases on all five sets $(p \leq 0.05){ }^{23}$ The authors concluded that $1 \mathrm{wk}$ of 25 $\mathrm{g} \cdot \mathrm{d}^{-1} \mathrm{Cr}$ supplementation increases muscular performances during repeated sets of jump squat and bench press exercises, likely due to the greater $\mathrm{TCr}$ pools from supplementation. ${ }^{23}$

Moreover, Earnest et al. reported similar findings in their investigation of $\mathrm{CrH}_{2} \mathrm{O}$ supplementation among ten highly weight-trained male participants and its effects on anaerobic power indices, muscular strength, and body composition ${ }^{47}$ Participants underwent three consecutive $30 \mathrm{~s}$ Wingate ergometer tests with 5 min off in between each Wingate trial. Peak anaerobic power was defined as the highest power achieved within a given $5 \mathrm{~s}$ work interval, while anaerobic work was denoted as the total amount of performed work within the $30 \mathrm{~s}$ work period. ${ }^{47}$ Further, the free weight bench press was used to assess 1RM as maximal muscular strength, followed by assessment of the number of repetitions achieved on the free weight bench press (70\% 1RM) until fatigue, cadenced by a metronome ( 60 beats $\left.\cdot \min ^{-1}\right) \cdot{ }^{47}$ Lastly, body composition was assessed using hydrostatic weighing techniques. Participants were either supplemented with (doubleblind) $\mathrm{Pl}(\mathrm{n}=4)$ or $\mathrm{CrH}_{2} \mathrm{O}\left(\mathrm{n}=4,20 \mathrm{~g} \cdot \mathrm{d}^{-1}\right)$ and after $14 \mathrm{~d}$ they re-tested their Wingate performances and after $28 \mathrm{~d}$ re-tested their bench-pressing exercises and anthropometric measures. It was unspecified if participants resistance trained during their supplementation protocols. For all post-test Wingate re-trials, the Cr group saw significant increases in anaerobic work $(13 \%, 18 \%, 18 \%$, respectively, $(p<0.05)$, while the Pl group saw no significant increases ${ }^{47}$ Further, several $5 \mathrm{~s}$ intervals over all three retrial Wingate periods showed significant $(p<0.05)$ increases (specific data not 
reported). ${ }^{47} 1 \mathrm{RM}$ bench press performance increased by $6 \%$ in the $\mathrm{Cr}$ group. ${ }^{47}$ Total lifting volume was significantly greater in the $\mathrm{Cr}$ group (absolute: $26 \%, p<0.01$; relative: $29 \%, p<0.001)$. No changes in body weight or fat free mass (FFM) were noted for the Pl group, though the Cr group saw significant increases in body weight but not FFM (body weight: $86.5 \pm 13.7$ vs. $88.2 \pm 14.1 \mathrm{~kg}, p<0.05$; FFM: $77.6 \pm 10.8$ vs. $79.2 \pm 11.6 \mathrm{~kg}, p=$ 0.054) ${ }^{47}$ The authors concluded that $\mathrm{CrH}_{2} \mathrm{O}$ could be utilized as an ergogenic aid to boost athletic performance as it increased submaximal resistance training volume. ${ }^{47}$

Balsom and colleagues found $\mathrm{CrH}_{2} \mathrm{O}$ supplementation to increase short-term, maximal cycling performance. ${ }^{44}$ Participants $(n=16$; resistance trained males) underwent two high-intensity, intermittent exercise protocols, once before and once after the supplementation of either $\mathrm{CrH}_{2} \mathrm{O}\left(5 \mathrm{~g} \mathrm{CrH}_{2} \mathrm{O}+1 \mathrm{~g}\right.$ glucose $\cdot \mathrm{d}^{-1}$; five times, daily, $\left.14 \mathrm{~d}\right)$ or $\mathrm{Pl}\left(6 \mathrm{~g} \cdot \mathrm{d}^{-1}\right.$ glucose; five times, daily). Participants were instructed to refrain from PA $24 \mathrm{~h}$ before each testing session but otherwise were instructed to maintain their typical daily PA. Each cycling protocol consisted of ten $6 \mathrm{~s}$ bouts of high-effort cycling at two different exercise intensities (130 revolutions $\cdot \mathrm{min}^{-1}, \sim 820 \mathrm{~W} ; 140$ revolutions $\cdot \mathrm{min}^{-1} \sim 880$ W). ${ }^{44}$ The latter of the two intensities were meant to induce fatigue during the $10 \mathrm{~s}$ exercise bouts while the former was meant to allow for participants to execute the same amount of work pre and post trials. The Pl group exhibited no significant improvements in any of the assessed physiological measures.$^{44}$ In the 140-revolution trial, there was significantly increased performance ( +10 revolutions $\left.\cdot \mathrm{min}^{-1}\right)$ towards the end (4-6 s, $p<$ 0.05) of each bout of exercise when the participants were supplemented with $\mathrm{CrH}_{2} \mathrm{O} .{ }^{44}$ The authors therefore concluded that $\mathrm{CrH}_{2} \mathrm{O}$ ingestion allowed prolonged muscular performance at higher intensities. ${ }^{44}$ They attributed this to an enhanced $\mathrm{PCr}$ pool in the 
resting state before exercise, in addition to an accelerated resynthesis of $\mathrm{PCr}$ during the recovery periods. ${ }^{44}$ Thus, Cr supplementation postpones the onset of muscular fatigue during repeated bouts of near-maximal exercise. ${ }^{44}$

Sprinting performance has been shown to be enhanced after $\mathrm{CrH}_{2} \mathrm{O}$ supplementation by Earnest and colleagues. ${ }^{109}$ Their investigation was to determine if supplementation of $\mathrm{CrH}_{2} \mathrm{O}$ would enhance anaerobic, intermediate-length, treadmill running to exhaustion. Investigators sought to see if anaerobic capacity, and time to

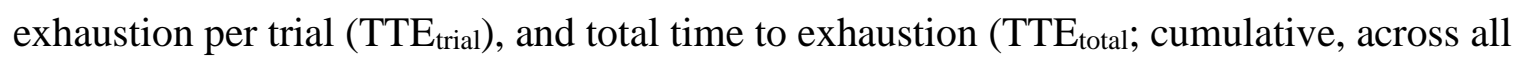
trials) could be enhanced with $\mathrm{CrH}_{2} \mathrm{O}$ supplementation for bouts of work lasting up to 90 s. Eleven male participants $(n=11)$ received either a glucose $\mathrm{Pl}$ or $\mathrm{CrH}_{2} \mathrm{O}$ treatment (20 $\mathrm{g} \cdot \mathrm{d}^{-1}, 4 \mathrm{~d}$ and $10 \mathrm{~g} \cdot \mathrm{d}^{-1}, 6 \mathrm{~d}$ ) while maintaining their normal PA routines during the treatment period. They performed two treadmill runs to exhaustion at individually prescribed grades with 8 min of rest between runs. ${ }^{109}$ Participants executed the two exhaustive treadmill runs at $214 \mathrm{~m} \cdot \mathrm{min}^{-1}$ at either a 10,15 , or $20 \%$ grade. ${ }^{109} \mathrm{TTE}_{\text {trial }}$ and TTE $_{\text {total }}$ were measured as a sum of both run trials. Results showed that there was a significant improvement for the Cr group for $\mathrm{TTE}_{\text {total }}$ with a $5.7 \mathrm{~s}$ increase $(p=0.05)$ and a decrease of $2 \mathrm{~s}$ in the $\mathrm{Pl}$ condition (exhausted faster). ${ }^{109} \mathrm{TTE}_{\text {total }}$ was significantly enhanced in the posttest trial for the Cr group (pre-test: $176.5 \pm 11.4 \mathrm{~s}$; posttest: $182.2 \pm$ 14.6 s). ${ }^{109}$ Researchers also measured blood lactate levels, and as expected, as TTE increased, so too did the bioenergetic dependency on anaerobic glycolysis, and thus, the increased levels of blood lactate. ${ }^{24}$ They concluded that the increased TTE total was attributed to greater TTE capability for each bout and thus, Cr supplementation may 
contribute to longer, intermediate-duration, near-maximal performances that are interval in nature. ${ }^{109}$

Swimming performance has also been found by Grindstaff et al. to be enhanced by $\mathrm{CrH}_{2} \mathrm{O}$ supplementation. ${ }^{110}$ The authors had eighteen competitive swimmers, male and female, supplement with either $\mathrm{CrH}_{2} \mathrm{O}\left(21 \mathrm{~g} \cdot \mathrm{d}^{-1}\right)$ or Pl (maltodextrin, $\left.21 \mathrm{~g} \cdot \mathrm{d}^{-1}\right)$ for $9 \mathrm{~d}$ during their training sessions. Both before and after the supplementation protocol, participants executed three 100-m (long-course) freestyle sprint-swims, and three $20 \mathrm{~s}$ maximal-effort, arm ergometer sprint tests (prone), both with $60 \mathrm{~s}$ of rest/recovery between exercise bouts. ${ }^{110}$ Following $\mathrm{CrH}_{2} \mathrm{O}$ supplementation, participants in this group swam significantly faster than the $\mathrm{Pl}$ group in the $100 \mathrm{~m}$ swim $\left(\mathrm{CrH}_{2} \mathrm{O}\right.$ : Heat $1:-0.27 \pm$ $0.3 \mathrm{~s}$; Heat-2: $-0.93 \pm 0.4 \mathrm{~s}$; Heat-3: $-0.36 \pm 0.3 \mathrm{~s} ;$ Pl: Heat-1: $0.86 \pm 0.3 \mathrm{~s}$, Heat-2: $-0.40 \pm$ $0.5 \mathrm{~s}$, Heat-3: $0.02 \pm 0.3 \mathrm{~s}$ ), significantly improved heat- 2 swim time, and showed a tendency to better their cumulative swim times for all three $100 \mathrm{~m}$ swims $(p=0.057) .{ }^{110}$ As a whole, $\mathrm{CrH}_{2} \mathrm{O}$ supplemented participants decreased their swim times by $-1.57 \pm 0.8$ $\mathrm{s}$ in comparison to the $\mathrm{Pl}$ group which increased their swim times by $0.48 \pm 0.6 \mathrm{~s}$ ( $p=$ 0.057). ${ }^{110}$ As for the ergometer for the upper extremity, sprint performance was significantly increased for the first of the three trials and in comparison to the Pl group, they showed $7.8 \%, 5.3 \%$, and $0.5 \%$ increases in performance, respectively, across all three trials. ${ }^{110}$ The authors concluded that $\mathrm{CrH}_{2} \mathrm{O}$ supplementation may enhance repetitive sprint-swim performance among competitive junior swimmers. ${ }^{110}$ Again, it is important to note that not all studies have found $\mathrm{CrH}_{2} \mathrm{O}$ supplementation to instigate ergogenic benefits. ${ }^{82,111-117}$ It remains uncertain as to why there has been some discrepancies in the literature, though it has been suggested the 
disparities may perhaps be due to: 1) placebo effects, 2) differing performance tasks used across studies, 3) small magnitudes of treatment effects, 4) relatively vast test-retest reliability error for the measurement of the given performance tasks, and 5) most likely because $\mathrm{Cr}$ supplementation is meant to increase intramuscular $\mathrm{TCr}$ stores, and as will be reviewed below, not everyone positively responds to $\mathrm{Cr}$ supplementation when consumed by itself. $^{26}$

As for the above studies that found positive performance effects associated with the oral supplementation with $\mathrm{CrH}_{2} \mathrm{O}$, they shared many common variables in terms of methodologies. For instance, nearly all the studies mentioned had only male participants. This alone disregards any discrepancies that may have been prevalent had female participants been included in the data sets. Indeed, one study noted that women showed less absolute increases in lean body mass after $\mathrm{CrH}_{2} \mathrm{O}$ supplementation versus their male counterparts, which was attributed to their smaller muscle mass, by nature. ${ }^{118}$ This may also indicate that women have altered $\mathrm{Cr}$ uptake abilities in comparison to men, and thus, it is important that women be included in future $\mathrm{Cr}$ studies.

Moreover, all the studies investigated near-maximal PA that was interval in nature. This calls for brief periods of rest/recovery between bouts of exercise, which allows for the ATP-PCr energy system to recover ATP levels by way of PCr hydrolysis. ${ }^{29,42,48}$ As the number of exercise trials increased per a given study, so too did the effects of the Cr treatments. While some acute performance increases occurred as well (eg, trial-1 on upper-extremity ergometer testing and 1RM bench press performance), the majority of the ergogenic benefits came from repeated bouts of executing a single performance task. ${ }^{110}$ 
As for the supplemental protocols, participants who were in the experimental $\mathrm{Cr}$ groups were typically supplemented with about $20-30 \mathrm{~g} \mathrm{CrH}_{2} \mathrm{O} \cdot \mathrm{d}^{-1}$. This dose was shown by Harris and colleagues to adequately increase intramuscular $\mathrm{TCr}$ content among most participants, and thus, has been used in the hundreds of $\mathrm{Cr}$ studies since. ${ }^{42}$ Supplemental protocols in the above literature ranged from acute to somewhat long-term, and all were associated with positive performance outcomes. This is likely because, as will be discussed in the following section, most $\mathrm{Cr}$ uptake by the body occurs within the first couple of supplementation days and decreases thereafter. ${ }^{42,85,119}$

In all, overwhelmingly more studies than not have found $\mathrm{Cr}$ supplementation to have positive performance outcomes when appropriately dosed and when the selected exercise protocol reflects the function of the ATP-PCr energy system than not. To best achieve these ergogenic benefits, it is imperative that $\mathrm{Cr}$ uptake by the body and skeletal musculature be maximized, which will be reviewed in the next section.

Creatine Monohydrate: Uptake and Retention Assessed via Urinalysis

Inulin increases caused by the intake of simple $\mathrm{CHO}$ has been shown to augment Cr retention in skeletal muscle. ${ }^{81}$ Thus, this section is dedicated to studies not supplementing $\mathrm{Cr}$ with simple $\mathrm{CHO}$. This section is dedicated to studies that investigated $\mathrm{CrH}_{2} \mathrm{O}$ supplementation and its ability to be absorbed by the intestines and retained by the body upon ingestion.

Among the first researchers to investigate oral $\mathrm{Cr}$ supplementation and its ability to be taken up by the body by way of tracing the $\mathrm{Cr}$-creatinine $(\mathrm{Cn}$; sole end product of Cr breakdown) balance via the urine, were Chanutin and Colleagues, in $1925 .{ }^{85}$ For this experiment, the authors of the study also served as the participants ( $n=2$, males). $2 \mathrm{wk}$ 
prior to the start of the study, participants followed a Cr-free diet (no meat or fish). Further, participants engaged in daily, non-vigorous PA throughout the course of the study, with activities being varied and unspecified. This $2 \mathrm{wk}$ period served as their control period from which they took their basal urine tests (participant 1 average daily outputs: $\mathrm{Cn}=1.51 \mathrm{~g} ; \mathrm{Cr}$ retained $=\mathrm{N} / \mathrm{A}$; extra $\mathrm{Cn}$ eliminated $=\mathrm{N} / \mathrm{A}) .{ }^{85}$ The experimental periods lasted for 29 (participant 1) and $44 \mathrm{~d}$ (participant 2), and the administered $\mathrm{CrH} 2 \mathrm{O}$ doses were either 10 or $20 \mathrm{~g} \cdot \mathrm{d}^{-1}$. Participant 1 first supplemented with $10 \mathrm{~g} \cdot \mathrm{d}^{-1}$ for the duration of $10 \mathrm{~d}$ (average daily outputs $(\mathrm{g})$ : $\mathrm{Cn}=6.19 ; \mathrm{Cr}$ retained $=4.54$; extra $\mathrm{Cn}$ eliminated $=0.60) .{ }^{85}$ Following, this participant ingested $20 \mathrm{~g} \cdot \mathrm{d}^{-1}$ which lasted for $8 \mathrm{~d}$ (average daily outputs $(\mathrm{g}): \mathrm{Cn}=16.45 ; \mathrm{Cr}$ retained $=4.23 ;$ extra $\mathrm{Cn}$ eliminated $=1.93) .{ }^{85}$ Following, participant 1 underwent a $2 \mathrm{~d}$ period where was consumed $10 \mathrm{~g} \cdot \mathrm{d}^{-1}$ again (average daily outputs $(\mathrm{g}): \mathrm{Cn}=11.43 ; \mathrm{Cr}$ retained $=-0.21 ;$ extra $\mathrm{Cn}$ eliminated $=1.16$ ), then a final, $2 \mathrm{~d}$ period where no $\mathrm{Cr}$ was administered (average daily outputs $(\mathrm{g}): \mathrm{Cn}=$ 3.71; $\mathrm{Cr}$ retained $=\mathrm{N} / \mathrm{A}$; extra $\mathrm{Cn}$ eliminated $=0.65) .{ }^{85} \mathrm{He}$ followed a different protocol, followed a control period (average daily outputs $(\mathrm{g})$ : $\mathrm{Cn}=1.61 ; \mathrm{Cr}$ retained $=\mathrm{N} / \mathrm{A}$; extra Cn eliminated $=\mathrm{N} / \mathrm{A})$, followed by three, $10 \mathrm{~d}\left(10 \mathrm{~g} \cdot \mathrm{d}^{-1}\right)$, supplemental periods (average daily outputs $(\mathrm{g})$ : $\mathrm{Cn}=6.37 ; \mathrm{Cr}$ retained $=4.48 ;$ extra $\mathrm{Cn}$ eliminated $=0.62$ : Period 2 average daily outputs $(\mathrm{g}): \mathrm{Cn}=10.10 ; \mathrm{Cr}$ retained $=1.35$; extra $\mathrm{Cn}$ eliminated $=1.22$ : Period 3 average daily outputs $(\mathrm{g}): \mathrm{Cn}=10.44 ; \mathrm{Cr}$ retained $=0.816$; extra $\mathrm{Cn}$ eliminated $=$ 1.03), a $5 \mathrm{~d}\left(10 \mathrm{~g} \cdot \mathrm{d}^{-1}\right)$, supplemental period (average daily outputs (g): $\mathrm{Cn}=10.06 ; \mathrm{Cr}$ retained $=1.09$; extra Cn eliminated $=0.93$ ), and concluded with $2 \mathrm{~d}$ of no $\mathrm{Cr}$ supplementation (average daily outputs $(\mathrm{g})$ : $\mathrm{Cn}=2.82 ; \mathrm{Cr}$ retained $=\mathrm{N} / \mathrm{A}$; extra $\mathrm{Cn}$ eliminated $=\mathrm{N} / \mathrm{A}){ }^{85}$ The first few $\mathrm{d}$ of $\mathrm{Cr}$ feeding allowed for very high $\mathrm{Cr}$ retention by 
the body (Participant 1: d 1, $5.91 \mathrm{~g}, \mathrm{~d} 2,5.32 \mathrm{~g}$; Participant 2: d 1, $6.80 \mathrm{~g}, \mathrm{~d} 2,6.15 \mathrm{~g}){ }^{85}$ However, from these points forth, gradual decreases in the retention of $\mathrm{Cr}$ in the body are noted with coincidental increases in urinary Cn levels. ${ }^{85}$ Both participants had approximately $115 \mathrm{~g}$ of baseline intramuscular $\mathrm{Cr}$ content and at the end of their respective experimental periods, Participant 1 retained $58 \mathrm{~g}$ of the $270 \mathrm{~g}$ (assumed in the skeletal muscle tissue) total $\mathrm{Cr}$ consumed over the 29 d period, while Participant 2 retained $38 \mathrm{~g}$ of the $340 \mathrm{~g}$ (assumed in the skeletal muscle tissue) consumed over the $44 \mathrm{~d}$ period. ${ }^{85}$ This would equate to an elevation in intramuscular $\mathrm{Cr}$ storage of $33 \%$ (Participant 1) and 50\% (Participant 2). ${ }^{85}$ From these findings, the authors concluded that 1) intestinal absorption is approximately $100 \%$ (via urinalysis), 2) Cn excretion gradually increases as $\mathrm{Cr}$ supplementation continues, 3) most of the $\mathrm{Cr}$ retained by the body takes place within 1-2 d of supplementing, and 4) approximately $90 \%$ of the ingested $\mathrm{Cr}$ is excreted in the urine with prolonged supplementation, beyond the first few days. ${ }^{85}$

A study by Harris et al. is much more recent and sought to see if doses of orally supplemented $\mathrm{CrH}_{2} \mathrm{O}$ were 1) retained by the body and 2) increased intramuscular $\mathrm{Cr}$ content. ${ }^{1}$ There were 17 participants (10 males, 7 females) between the ages of 20 and 62 , two of which were vegetarian, and all with varied fitness levels (untested). Participants were not instructed to change their diets nor change their daily PA. $20 \mathrm{~g} \cdot \mathrm{d}^{-1}(5 \mathrm{~g}$, four times, daily) $\mathrm{CrH}_{2} \mathrm{O}$ was consumed by Participants 1 and 2 (4.5 d), Participants 3 and 4 (7 d), and Participant 5 (10 d). $5 \mathrm{~g} \cdot \mathrm{d}^{-1}$ (6 times, daily) $\mathrm{CrH}_{2} \mathrm{O}$ was supplemented by Participants 6-8 (7 d) and Participants 9-12 (alternate d, $21 \mathrm{~d}$ ). The rest of the participants $(n=5)$ underwent similar doses but were tested under exercised conditions to note any training effects associated with the $\mathrm{Cr}$ consumption and thus, will be disregarded by this 
section of the review as it is solely focused on Cr retention by the body. Muscle biopsies, blood samples, and $24 \mathrm{~h}$ urine samples were taken from all participants, though only four participants had complete urine data collected. A $5 \mathrm{~g}$ dose of $\mathrm{CrH}_{2} \mathrm{O}$ (about that found in $1.1 \mathrm{~kg}$ of raw steak) was selected based on blood sampling of participants as $7 \mathrm{~h}$ of sampling at this dose provided a high mean peak concentration of approximately 795 ( \pm 104) $\mu \mathrm{mol} \cdot \mathrm{l}^{-1}$ at 1 hour with a stable Cn concentration of only $70-100 \mu \mathrm{mol} \cdot \mathrm{l}^{-1}$, as compared to a $1 \mathrm{~g}$ administered dose (plasma $\mathrm{Cr}$ concentration only approximately 1 $\left.\mu \mathrm{mol} \cdot \mathrm{l}^{-1}\right){ }^{1}$ Though there were only four complete urine collection analyses, consistent even with the incomplete analyses, it revealed that the greatest uptake of $\mathrm{Cr}$ occurred during the first $2 \mathrm{~d}$, regardless of dose $(20-30 \mathrm{~g} \mathrm{Cr}) .{ }^{1}$ Over the first $3 \mathrm{~d}$ for participants 13 15 (5 g, 6 times a day), renal excretion of the total $30 \mathrm{~g}$ dose was $40 \% \pm 14 \%, 61 \% \pm 3 \%$, and $68 \% \pm 15 \%$, respectively. ${ }^{1}$ Among these participants during these first $2 \mathrm{~d}$, the estimated mean $\mathrm{Cr}$ uptake by the muscle was approximately $17.7 \pm 3.4 \mathrm{~g}$ which equates to approximately $32 \%$ of the administered $\mathrm{Cr}$ dose, $20 \%$ as $\mathrm{PCr} .{ }^{1}$ From d 2 to $\mathrm{d} 4, \mathrm{Cr}$ uptake gradually increased another $9.1 \pm 1.6 \mathrm{~g}$, approximately $50 \%$ of what was taken up the first $2 \mathrm{~d} .{ }^{1}$ This differed from the previous study in that $100 \%$ of the Cr was reported to be digested. In all, an intramuscular Cr concentration increased by approximately 25 $\mathrm{mmol} \cdot \mathrm{kg}^{-1}$ (dry muscle; DM), however, with between-subject variation rather vast (2-40 $\left.\mathrm{mmol} \cdot \mathrm{kg}^{-1}(\mathrm{DM})\right) .{ }^{1}$ This variation should be expected given the varied supplementation protocols participants were assigned to.

Hultman and colleagues followed up the Harris et al. study in 1996 with their investigation of $\mathrm{Cr}$ retention among men. ${ }^{119}$ Thirty-one men participated in this study which had four different experiments (each participant assigned to only one) and lasted 
for $2 \mathrm{y}$. No participant was considered highly trained, though all reported being at least somewhat physically active. Further, participants were to maintain their usual diets and to refrain from strenuous PA throughout each experiment. Of the four experimental groups, Group-4 was the only group to test for $\mathrm{Cr}$ excretion via the urine. Group-4 consisted of seven participants $($ age $=23 \pm 1.8 \mathrm{y}$, body mass $=74.3 \pm 5.4 \mathrm{~kg}) .{ }^{119}$ Each participant consumed $20 \mathrm{~g}$ of the Pl (Maxijul glucose polymer) for $5 \mathrm{~d}$ and $24 \mathrm{~h}$ urine samples were collected 1 and $6 \mathrm{~d}$ prior to the start of $\mathrm{Pl}$ ingestion. ${ }^{119}$ Urine collection also took place on Pl ingestion $\mathrm{d} 1,3$, and 5 , and then on $\mathrm{d} 8,11,15,22$, and 25 for a $20 \mathrm{~d}$ period that followed the placebo $(\mathrm{Pl})$ ingestion period. Following this period, participants then repeated the previously mentioned procedures, but with $20 \mathrm{~g} \cdot \mathrm{d}^{-1}$ of $\mathrm{Cr}$ rather than the $\mathrm{Pl}$. These supplemental periods were originally planned to last $6 \mathrm{~d}$ each, but as previously found in Groups-1 and -2, intramuscular Cr retention was peaked after d-5 and started to decline after $\left(\mathrm{d} 5: 142.6 \pm 2.3 \mathrm{mmol} \cdot \mathrm{kg}^{-1} \mathrm{DM}\right.$; $\mathrm{d}$ 6: $\left.147.2 \pm 4.7 \mathrm{mmol} \cdot \mathrm{kg}^{-1} \mathrm{DM}\right) .{ }^{119} \mathrm{The}$ authors reported that there was a vast between-subject variation for $\mathrm{Cn}$ excretion among participants for the first $20 \mathrm{~d}$ of this experimental trial, though on the final day 20 they could obtain a post-Cr consumption average for $\mathrm{Cn}$ excretion $\left(2.8 \mathrm{mmol} \cdot \mathrm{d}^{-1}>\mathrm{Pl}\right.$ ingestion $(p<0.05)) .{ }^{119}$ The majority of the $\mathrm{Cr}$ retained by the muscle tissue took place during the first $2 \mathrm{~d}$ of $\mathrm{Cr}$ supplementation $(\sim 30 \%)$ as compared to only $15 \%$ on $\mathrm{d} 2-4{ }^{119}$ The mean increase in intramuscular TCr across all experimental groups who ingested 20 $\mathrm{g} \cdot \mathrm{d}^{-1}$ over the $6 \mathrm{~d}$ period (high-dose, fast $\mathrm{Cr}$ load) was $20 \mathrm{mmol} \cdot \mathrm{kg}^{-1} \mathrm{DM}$. Other groups (not mentioned earlier, no urinalysis) supplemented with only $3 \mathrm{~g} \cdot \mathrm{d}^{-1}$ over a $28 \mathrm{~d}$ period (a low-dose, long-duration Cr load), and while accumulation of $\mathrm{Cr}$ was slower, the $28 \mathrm{~d}$ result proved to show no difference in intramuscular TCr retention. ${ }^{119}$ It is important to 
note, however, that the sample size in this study was small $(\mathrm{n}=13)$ and additional studies are needed to draw more conclusive results.

Enhanced uptake of Cr may help negate typical anecdotes of associated gastrointestinal discomfort or others, which though are uncommon, are reviewed below. $\underline{\text { Creatine Monohydrate: Adverse Effects }}$

There have been numerous reported adverse effects associated with $\mathrm{CrH}_{2} \mathrm{O}$ supplementation, ranging from gastrointestinal distress to muscle and cardiovascular issues. ${ }^{26}$ However, Terjung and colleagues state that these findings are not definitive are not enough to deem $\mathrm{Cr}$ supplementation as a health risk. ${ }^{26}$ At the same time, they state, it cannot be assumed that $\mathrm{Cr}$ supplementation is free from health risks; more research is needed. ${ }^{26}$

One study by Vandebuerie and colleagues demonstrated that timing of $\mathrm{Cr}$ supplementation may be responsible for the reported associated stomach issues. ${ }^{68}$ Twelve male, non-vegetarian participants underwent a $2 \mathrm{~h}$ and 30 min endurance cycling protocol on their own bicycles mounted to an electromechanically-braked system. Once the participants cycled and achieved exhaustion at their 4 mmol lactate thresholds, they immediately followed with five maximal sprints for $10 \mathrm{~s}$, with 2 min intervals of recovery. Prior to the exercise protocol, all participants were "Cr-loaded," as they consumed $25 \mathrm{~g} \cdot \mathrm{d}^{-1}(5 \mathrm{~d})$, and some participants were given $\mathrm{Cr}\left(5 \mathrm{~g} \cdot \mathrm{h}^{-1}\right)$ or Pl during the workouts. ${ }^{68}$ Four out of six participants who consumed the Cr during the exercise protocol reported post-exercise "distress," while the Pl treatment during exercise yielded two reports of distress. ${ }^{68}$ 
Juhn et al. and Schnirring's respective studies reported muscle cramping, stiffness, and strains among some of their athlete-participants. ${ }^{120}$ Similarly, Tarnopolsky et al. found that among 81 participants who had neuromuscular disease, just one participant reported muscular cramping subsequent to supplementing with $10 \mathrm{~g} \cdot \mathrm{d}^{-1}(5 \mathrm{~d})$ followed by $5 \mathrm{~g} \cdot \mathrm{d}^{-1}(5 \mathrm{~d}) .{ }^{120}$ When they put this participant under the same experimental Cr conditions, however, they did not complain of any muscle cramps the following session, suggesting that $\mathrm{Cr}$ may not have been responsible. ${ }^{120}$

There have also been anecdotes of hypertension among those who supplement with $\mathrm{Cr} .{ }^{26}$ However, Mihic and colleagues found via double-blind procedures that shortterm $\mathrm{Cr}$ supplementation $\left(20 \mathrm{~g} \cdot \mathrm{d}^{-1}, 5 \mathrm{~d}\right)$ among young male and female participants had no effects on mean, systolic, or diastolic blood pressures. ${ }^{66}$ Peeters et al. found in a similar study that the same supplemental Cr protocol yielded no blood pressure effects over a longer duration of time ( $6 \mathrm{wk}, 20 \mathrm{~g} \cdot \mathrm{d}^{-1}(3 \mathrm{~d}), 10 \mathrm{~g} \cdot \mathrm{d}^{-1}$ maintenance) ${ }^{67}$ Two more studies found that blood pressure was not affected among participants with congestive heart failure who supplemented with $\operatorname{Cr}\left(20 \mathrm{~g} \cdot \mathrm{d}^{-1}, 5 \mathrm{~d}\right.$ and $\left.20 \mathrm{~g} \cdot \mathrm{d}^{-1}, 10 \mathrm{~d}\right){ }^{121,122}$

Lastly, Cr supplementation has been scrutinized by claims that it unfavorably alters renal functioning because its consumption increases urinary output of $\mathrm{Cr}$ and $\mathrm{Cn}$ and would therefore be expected to increase Cn concentrations in the plasma. ${ }^{26}$ Shortduration $\left(20 \mathrm{~g} \cdot \mathrm{d}^{-1}, 5 \mathrm{~d}\right)$ supplementation of $\mathrm{Cr}$ has been found to have no effects on glomerular filtration rate. ${ }^{65,123}$ Moreover, athletes supplementing with $\mathrm{Cr}$ for up to $5 \mathrm{y}$ had no effect on renal functioning. ${ }^{50}$

There have been numerous anecdotes associated with the consumption of large quantities of $\mathrm{CrH}_{2} \mathrm{O}$. As discussed in the next session, this has been attributed to the lack 
of intestinal absorption of $\mathrm{CrH}_{2} \mathrm{O}$ through the intestinal cells. ${ }^{69,76,87}$ Nevertheless, these anecdotes are typically single reports, and when in some cases, the affected participant is re-tested under the same $\mathrm{Cr}$ conditions, the report of distress does not reoccur. However, because of these perceived issues, companies have strived to come up with alternative forms of commercially available $\mathrm{Cr}$ that can be better taken up by the body, reduce these anecdotal reports of ill-effects, and still provide the ergogenic benefits found with the supplementation of $\mathrm{CrH}_{2} \mathrm{O} . \mathrm{CrHCl}$ is among the latest of these new forms, and shows promise in solubility and intestinal uptake abilities.

Creatine $\mathrm{HCl}$ : Solubility and Intestinal Uptake

Nutrients can make it through the epithelia of the intestinal tract through numerous mechanisms, including active transport, facilitated transport, diffusion, or paracellular pathways. ${ }^{124}$ Because $\mathrm{Cr}$ shares similar structural characteristics to simple amino acids it may enter systemic circulation through peptide transporters, amino acid transporters, or specialized transporters (eg, taurine), or possibly even through the paracellular route. ${ }^{124,125}$ Karlsson and colleagues reported that $\mathrm{Cr}$ has a molecular weight of $131 \mathrm{~g} \cdot \mathrm{mol}^{-1}$, a net positive charge, and an approximate partition coefficient of -2.7 , and thus, should bypass the intestinal epithelia through paracellular pathways. ${ }^{126}$ However, Dash et al. found $\mathrm{CrH}_{2} \mathrm{O}$ to have very poor ability to bypass the intestinal epithelia. ${ }^{124}$ This is likely because the aqueous solubility of $\mathrm{CrH}_{2} \mathrm{O}$ has been found to be only approximately $16.6 \pm 0.3 \mathrm{mg} \cdot \mathrm{mL}^{-1} \cdot{ }^{127}$ Aqueous solubility of $\mathrm{CrHCl}$ was found to be 38 times greater than that of $\mathrm{CrH}_{2} \mathrm{O} \cdot{ }^{87}$

$\mathrm{CrHCl}$ was brought to the market as a dietary supplement around 2009 as an alternative form of supplemental $\mathrm{Cr}$, more acidic than $\mathrm{CrH}_{2} \mathrm{O}$, that is supposed to be 
much more soluble in liquid and consequently, better absorbed by the intestines. ${ }^{76}$ To make $\mathrm{CrHCl}$, the manufacturer mixes $\mathrm{CrH}_{2} \mathrm{O}$ with acetyl chloride and ethanol is then added as a solvent. ${ }^{76}$ This solution precipitates a granular form of $\mathrm{HCl}$ salt of $\mathrm{Cr}$ after the solution is heated between approximately $24^{\circ} \mathrm{C}$ and $50{ }^{\circ} \mathrm{C} .{ }^{76}$ Lastly, the solution is reduced to ambient atmospheric temperature and pressure where the $\mathrm{CrHCl}$ granules are collected and packaged for commercial use and consumption by humans or livestock as a dietary supplement, in a solid, oral-dosage form, such as capsules or tablets. ${ }^{2}$

Gufford and colleagues investigated the aqueous solubility ability of $\mathrm{CrHCl}$ and other commercially available $\mathrm{Cr}$ salts in comparison to that of $\mathrm{CrH}_{2} \mathrm{O} .{ }^{87}$ The purpose of the study was to identify a water soluble Cr salt that would have increased solubility and bioavailability, a lower needed oral dose, and a decrease in side effects in comparison to $\mathrm{CrH}_{2} \mathrm{O}$. Each of the six salts underwent nuclear magnetic resonance, elemental analysis, and melting-point determination, followed by high performance liquid chromatography (HPLC). From there, determination of saturation solubility of each salt took place in deionized water by slowly adding it to $5 \mathrm{~mL}$ of solvent in glass bottles which were settled in a shaking water-glass $\left(25^{\circ} \mathrm{C}\right) .{ }^{87}$ Following, $2 \mathrm{~mL}$ aliquots were extracted and centrifuged $(11,000 \mathrm{rpm})$ for $5 \mathrm{~min} .{ }^{87} \mathrm{HPLC}$ was then used to determine $\mathrm{Cr}$ concentrations. All salts were found to be significantly more soluble than $\mathrm{CrH}_{2} \mathrm{O}$, with $\mathrm{CrHCl}$ producing the most significant increase $\left(\mathrm{CrHCl}: 709 \pm 7 ; \mathrm{CrH}_{2} \mathrm{O}: 17.1 \pm 0.4\right) .{ }^{87}$ The authors proposed that a contributing factor is likely due to the fact all of the saturated salt solutions were in highly acidic states (unbuffered water; $\mathrm{pH}$ 0.3-3.1) as compared to the $\mathrm{CrH}_{2} \mathrm{O}$ solution ( $\left.\mathrm{pH} 8.6\right) .{ }^{87}$ In biological fluid or neutral $\mathrm{pH}, \mathrm{Cr}$ is in its least-soluble, electrically-neutral state due to its 7.4 isoelectric point. ${ }^{87}$ 
In another study, Gufford and colleagues investigated the permeability of $\mathrm{CrHCl}$ across the human Caco-2 epithelial cell monolayers. ${ }^{69}$ Permeability of both $\mathrm{CrH}_{2} \mathrm{O}$ and $\mathrm{CrHCl}$ were investigated using the cell-line (epithelium of human intestine) from a human carcinoma of the colon (Caco-2). ${ }^{69}$ The epithelial cells were seeded into specialized, $24 \mathrm{~mm}$ diameter, polycarbonate membrane inserts at $60,000 \mathrm{cells} \cdot \mathrm{cm}^{2}{ }^{69}$ These cells were kept in a 5\% carbon dioxide environment for approximately $21 \mathrm{~d}$ and supplemented with $10 \%$ fetal bovine serum, from which point, merged monolayers were reached. ${ }^{69} 1.5 \mathrm{~mL}$ of simulated intestinal fluid in addition to $10 \mathrm{mM}$ of $\mathrm{CrHCl}$ replaced the apical compartment of the monolayers after a 30 min period of incubation. ${ }^{69}$ The highest permeability in the Caco-2 monolayers was noted for $\mathrm{CrHCl}$, as it was approximately 15-times greater than that of $\mathrm{CrH}_{2} \mathrm{O}\left(\mathrm{CrH}_{2} \mathrm{O}: 0.12 \pm 0.004 \mathrm{~cm} / \mathrm{s} ; \mathrm{CrHCl}\right.$ : $\left.4.3 \pm 0.4 \mathrm{~cm} \cdot \mathrm{s}^{-1}(p<0.05)\right) .{ }^{69}$

Per these studies, it is apparent that $\mathrm{CrHCl}$ is indeed a much more soluble form of $\mathrm{Cr}$ in aqueous solution in comparison to $\mathrm{CrH}_{2} \mathrm{O}$. Further, while $\mathrm{CrHCl}$ showed promise bypassing intestinal cells in vitro, TCr uptake by the body upon supplementing with it has yet to be quantified in a human model. Thus, the study at hand will be among the first to do so.

\section{$\underline{\mathrm{CrHCl} \text { and Resistance Training }}$}

Research investigating $\mathrm{CrHCl}$ supplementation and its effects on resistance training is lacking. To the author's knowledge, only three studies to date have considered $\mathrm{CrHCl}$ as an ergogenic aid.

The first study compared strength and body composition effects of a high $\mathrm{CrHCl}$

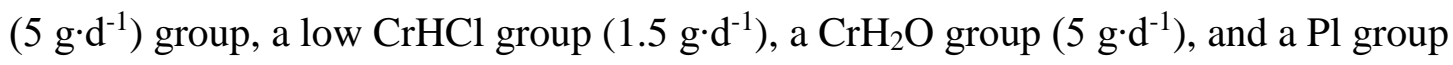


over a 4 wk period..$^{75}$ Participants $(n=30$; both sexes) were randomly divided into one of the four groups and underwent a given treatment while adhering to a prescribed $4 \mathrm{wk}$ resistance training protocol. 1RM bench press and leg press were assessed both pre- and post-experiment as well as body-composition (skin fold). 1RM leg press was significantly increased $(p<0.05)$ in all groups while $1 \mathrm{RM}$ bench press was only significantly increased in the low $\mathrm{CrHCl}$ group $(p=0.003) .{ }^{75}$ Between group differences were not found. Both $\mathrm{CrHCl}$ groups resulted in significantly decreased FM (high: $p=0.034$; low: $p=0.005$ ) while FFM was significantly increased only in the high $\mathrm{CrHCl}$ group. ${ }^{75}$ It was concluded that both $\mathrm{CrHCl}$ and $\mathrm{CrH}_{2} \mathrm{O}$ promote gains in strength but only $\mathrm{CrHCl}$ promotes significant changes in body composition with differences in doses, which contradicts other research showing that $\mathrm{CrH}_{2} \mathrm{O}$ can positively influence body composition (eg, increase fat free mass, decrease fat mass) ${ }^{75}$ However, it is important to note that participants in this study were asked to refrain from any form of resistance training $4 \mathrm{wk}$ prior to the start of the study, which may have had an impact on strength and body composition results.

Another study by Reuland investigated training effects associated with a single dose of $\mathrm{CrHCl}$ supplementation $\left(0.033 \mathrm{~g} \cdot \mathrm{kg}^{-1}\right.$ bodyweight, $30 \mathrm{~min}$ before testing) and differences across genders. ${ }^{128}$ This study investigated pre- and post-total training volume (TTV) on five repeated sets of the barbell bench press and the incline lying leg press exercises with 75 s rest between each set. Lab visits were separated by 48 h (paperwork, 1RM testing, control trial, and experimental trial) and participants were asked to refrain from exercise during these periods. Results for the leg press showed that women in the $\mathrm{Cr}$ and Pl groups all significantly increased TTV from the control to the experimental trial ( $p$ 
$=0.004, p=0.02$, respectively). ${ }^{128}$ Men in the $\mathrm{Cr}$ and $\mathrm{Pl}$ groups also significantly increased leg press TTV ( $p=0.03, p=0.003$, respectively) ${ }^{128}$ However, women in the $\mathrm{Cr}$ group had significantly higher score differences from the control to the experimental trials than their male counterparts $(p=0.01) .{ }^{128}$ Women's TTV for the bench press showed no significant differences from pre- to post-intervention in the experimental or control group $(p=0.2, p=0.21)$ and the same held true for men $(p=0.12 p=0.68) .{ }^{128}$ The authors concluded that the efficacy of $\mathrm{CrHCl}$ on resistance training remains unclear. Lastly, a study by Packer and colleagues investigated the acute effects of $\mathrm{CrHCl}$ supplementation over a $6 \mathrm{~d}$ period on 1RM performance on the barbell bench press, barbell deadlift, and CMJ among trained powerlifters. ${ }^{129}$ Participants $(n=9)$ were spread unevenly into three groups $\left(\mathrm{CrHCl}(\mathrm{n}=4)\right.$ : two doses at $0.750 \mathrm{mg} \cdot \mathrm{d}^{-1} ; \mathrm{CrH}_{2} \mathrm{O}(\mathrm{n}=3)$ : two doses at $\left.5 \mathrm{~g} \cdot \mathrm{d}^{-1} ; \mathrm{Pl}(\mathrm{n}=2)\right) .{ }^{129}$ Participants were instructed not to resistance train or perform any anaerobic-style PA during the $6 \mathrm{~d}$ intervention period. No statistically significant changes were found in $1 \mathrm{RM}$ on any of the three performance measures from pre- to post-treatment $(p>0.05) .{ }^{129}$ Percent-changes for all three performance tasks for the $\mathrm{CrHCl}, \mathrm{CrH}_{2} \mathrm{O}$ and $\mathrm{Pl}$ groups, respectively, were calculated (barbell back squat: $2.44 \%, 1.54 \%$, and $10.33 \%$; deadlift: $1.4 \%, 2.21 \%$, and $6.67 \%$; CMJ: $2.04 \%, 3.61 \%$, and $-2.15 \%$ ) and resulted in the conclusion that neither form of $\mathrm{Cr}$ as a dietary supplement is effective at augmenting 1RM on these three tasks over a $6 \mathrm{~d}$ supplemental period. ${ }^{129}$ Results contrary to the previous studies were likely produced due to a very small sample size and because participants were instructed not to exercise during the $6 \mathrm{~d} \mathrm{Cr}$ intervention period, which is counterintuitive due to the fact that exercised skeletal muscle tissue better retains $\mathrm{Cr}$ as shown by Harris and colleagues and once a muscle's $\mathrm{Cr}$ 
stores are full supplemented $\mathrm{Cr}$ is simply excreted in the urine. ${ }^{129}$ Moreover, 1RM performance does not truly mimic the ATP-PCr energy system where an influx of intramuscular $\mathrm{Cr}$ and $\mathrm{PCr}$ would be useful for ATP and $\mathrm{PCr}$ resynthesis during longer periods of near-maximal effort PA; likely, the ATP stores in the muscle prior to the 1RM attempts were being used as the sole energy source. Thus, Cr supplementation should not have been expected to increase performances on the respective 1RMs.

\section{Closing}

It has been established that the oral supplementation of $\mathrm{CrH}_{2} \mathrm{O}$ can enhance whole body and intramuscular levels of TCr, even more so when taken in conjunction with an insulin-stimulating companion. Because of this increase of intramuscular TCr, namely PCr, ATP can be resynthesized for longer durations of short-duration, maximal-intensity PA, especially when interval in nature with recovery-time in between exercise bouts to allow for further synthesis of ATP.

However, there have been many anecdotal reports of study participants who supplemented with high doses of $\mathrm{CrH}_{2} \mathrm{O}$ (20-30 g) who complained about issues, such as gastrointestinal distress and muscle cramps, with the former of the two being attributed to $\mathrm{CrH}_{2} \mathrm{O}$ 's lack of ability to bypass the intestinal cells due to its low solubility in aqueous solution. Thus, another form of $\mathrm{Cr}(\mathrm{CrHCl})$ was introduced to the market in 2009 as a form of $\mathrm{Cr}$ that is more soluble in aqueous solution and bypasses the intestinal epithelial cells at a much higher rate with the purpose of providing consumers with the ergogenic benefits of $\mathrm{CrH}_{2} \mathrm{O}$ without the reported ill-effects reported by those who supplement with it. However, there are only three studies to date looking at the ergogenic benefits 
associated with its consumption. Thus, the study at hand will be one of the first to investigate this. 


\section{CHAPTER THREE: METHODS}

\section{$\underline{\text { Participants }}$}

Sixteen healthy, resistance trained males between the ages of 18 and 34 y were recruited to participate in this study. Inclusion in the study required participants to have at least $1 \mathrm{y}$ of current, consistent (minimum of $3 \mathrm{~d} \cdot \mathrm{wk}^{-1}$ ) resistance training experience, which was verbally verified by the PI prior to the start of the study. Exclusion criteria, which was also verbally assessed prior to the start of the study, excluded participants who were not between the ages of 18 and $34 \mathrm{y}$, had less than $1 \mathrm{y}$ of current and consistent resistance training experience, used anabolic steroids, were vegans or vegetarians, diabetic, and/or were unwilling to cease the use of their current dietary supplement regimens.

Participation in this study was completely voluntary and required a signed, written informed consent (APPENDIX A) approved by the BSU Institutional Review Board (IRB \#103-MED17-003). The revised, 2017 version of the Physical Activity Readiness Questionnaire (PAR-Q; APPENDIX B) was distributed to all participants to ensure that they had no previous or current health conditions that would prevent them from being able to participate in this in the study. All screening information and collected data was handled with complete confidentiality. Only the PI had access to the participants' screening documents locked in a designated cabinet within BSU's Human Performance Laboratory (HPL). Collected data was accessed only by the PI. All participant information was kept electronically on a secured, BSU password-protected computer. 
Further, each participants' information was kept private and was stored using assigned IDs created by the PI of this study. The participant ID codes were kept in a separate location from the participant data.

$\underline{\text { Procedures }}$

A pre-post experimental design was followed, as the same group of participants were tested twice on the same variables before and after the $1 \mathrm{wk}$ treatment period.

The Cr hydrochloride $(\mathrm{CrHCl})$ supplement (NutraBio Creatine $\mathrm{HCl}$; NutraBio Labs, Middlesex, NJ) was administered in a 1 wk supply (28 g) to each participant, in $2 \mathrm{~g}$ doses (powdered form). Participants were instructed to take two, $2 \mathrm{~g}$ doses daily, $30 \mathrm{~min}$ pre-, and immediately following their respective daily resistance training workouts. On days when participants did not resistance train, they were instructed to consume a $4 \mathrm{~g}$ dose in the morning upon waking. To minimize any potential differences in rates of intestinal $\mathrm{Cr}$ absorption, all participants were instructed to mix the powder in identical volumes $(8 \mathrm{oz})$ of cold water and were asked to consume the mixture within a $5 \mathrm{~min}$ period from the end of mixing, starting from their first sip. ${ }^{78}$

Two wks prior to the start of the treatment period, participants agreed to cease their current use of dietary supplements, which served both as a $\mathrm{Cr}$ washout (allowing intramuscular TCr levels to return to pre-supplemented levels) and control period. ${ }^{40}$ Furthermore, participants agreed to refrain from consuming alcohol and engaging in any form of strenuous exercise $24 \mathrm{~h}$ before each testing protocol. ${ }^{78}$

During visit 1, participants completed all paperwork and completed their maximal countermovement vertical jump (CMJ) height and 1 repetition maximum (1RM) on the bench press. Participants were then asked to recall their typical daily dietary intakes and 
were asked to maintain similar caloric intakes throughout the course of the study (eg, make no major dietary changes, such as vast amounts of fast foods).

Participants were also asked to maintain their current resistance training splits and continue to resistance train a minimum of $3 \mathrm{~d} \cdot \mathrm{wk}^{-1}$. All participants reported resistance training during the treatment period (per their usual routines) at least $3 \mathrm{~d} \cdot \mathrm{wk}^{-1}$, per study requirements. Of the fifteen participants, about half $(n=8)$ reported resistance training 4 $\mathrm{d} \cdot \mathrm{wk}^{-1}$ while the remaining participants $(n=7)$ reported resistance training $5 \mathrm{~d} \cdot \mathrm{wk}^{-1}$ during the $7 \mathrm{~d}$ treatment period. All participants reported engaging in some form of a periodized, split-body training routine where each muscle major muscle group was only trained $1 \mathrm{~d} \cdot \mathrm{wk}^{-}$ ${ }^{1}$. No participant reported engaging in PA that was outside of their normal training routines.

Pre- and post-intervention body measures were taken on visits 2 and 3 in the BSU HPL (height $(\mathrm{cm})$ : standard anthropometry stadiometer; body weight (BW; $\mathrm{kg}$ ) and body composition: whole body densitometry via air displacement (Bod Pod; COSMED USA, Concord, CA) for fat free mass (FFM; kg) and fat mass (FM; kg), followed by the respective upper and lower body muscular performance assessments. Completion of visit 2 took approximately $45 \mathrm{~min}$ to complete and initiated the $1 \mathrm{wk}$ treatment period, as participants were distributed their 1 wk portions of the $\mathrm{CrHCl}$ treatment. Visit 3 was identical to visit 2 as participants repeated the performance and body composition assessments described above.

The study protocol is displayed below (Table 3.1): 
Table 3.1 Study Protocol by Week

\begin{tabular}{|l|l|l|}
\hline Time (wk) & Activity & Data \\
\hline 0 & Recruitment & None \\
\hline $0-2$ & $\begin{array}{l}\text { No supplements (Cr wash-out) } \\
\text { Visit 1 (1 h): } \\
\text { Pre-screening/Introduction } \\
\text { 1RM bench press testing } \\
\text { Maximal CMJ testing } \\
\text { Protocol familiarization } \\
\text { Assess 'typical" daily diet intake }\end{array}$ & $\begin{array}{l}\text { 1RM bench press } \\
\text { Maximal vertical jump height } \\
\text { Typical daily diet intake }\end{array}$ \\
\hline 2 & $\begin{array}{l}\text { Visit 2 (45 min): } \\
\text { Body measures (height, weight, body } \\
\text { composition) } \\
\text { Pre-treatment bench press test } \\
\text { Pre-treatment lower body jump test } \\
\text { Distribute CrHCl supplement }\end{array}$ & $\begin{array}{l}\text { Major dietary changes (if } \\
\text { any)? } \\
\text { Other supplement } \\
\text { consumption? } \\
\text { Body measures } \\
\text { Bench press repetitions } \\
\text { Number of jumps completed }\end{array}$ \\
\hline $2-3$ & $\begin{array}{l}\text { Daily supplement intake (pre-and } \\
\text { post-workout) }\end{array}$ & $\begin{array}{l}\text { None } \\
\text { Visit 3 (45 min): } \\
\text { Body measures (height, weight, body } \\
\text { composition) } \\
\text { Post-treatment bench press test } \\
\text { Post-treatment lower body jump test }\end{array}$ \\
\hline 3 & $\begin{array}{l}\text { Major dietary changes (if } \\
\text { any)? } \\
\text { Other supplement } \\
\text { Consumption? } \\
\text { Body measures } \\
\text { Bench press repetitions } \\
\text { Number of jumps completed }\end{array}$ \\
\hline
\end{tabular}

$\underline{\text { Measures }}$

\section{$\underline{\text { Purity of the } \mathrm{CrHCl} \text { Product }}$}

$\mathrm{CrHCl}$ product samples were tested and analyzed for purity using an Agilent 1100 Series High-Performance Liquid Chromatography (HPLC) Value System machine (Agilent Technologies, Waldbronn, Germany). ${ }^{130}$ The Agilent 1100 HPLC machine allows for the separation, identification, and quantification of all components of a given mixture, with efficient mixing and pulse-free delivery of solvents in order to provide fast and accurate analytical results of a given sample. ${ }^{130} 10 \mathrm{mg}$ of $\mathrm{CrHCl}$ was placed in $10 \mathrm{~mL}$ 
of Nanopure Water, which yielded a concentration of $6.7 \mathrm{mM}$. Solvents used in the HPLC included ammonium formate (aqueous) and acetonitrile (organic). Sample run time in the HPLC machine lasted $10 \mathrm{~m}$, and progressed in this fashion:

- 0-3 min: Solution is $70 \%$ ammonium formate $/ 30 \%$ acetonitrile;

- 3-8 min: solution is 30\% ammonium formate/70\% acetonitrile;

- 8-10 min: solution is $70 \%$ ammonium formate/30\% acetonitrile. $\underline{1 R M}$ Bench Press

1RM on the bench press was initially estimated using the Epley Formula:

$$
I R M=[1+(0.0333 \times \text { repetitions completed })] \times \text { weight lifted. }{ }^{131}
$$

Participants estimated a weight for which they could perform ten repetitions on the barbell bench press. This weight was multiplied by 1.33 (per the Epley Formula), which yielded an approximate 1RM and a starting point for testing. ${ }^{131}$ Testing began with a progressive barbell bench press warmup, starting with 3-5 repetitions at a very light weight (50\% of established, estimated 1RM), resting for 2 min, completing 2-4 repetitions at $70 \%$ of the estimated $1 \mathrm{RM}$, resting for 4 min, completing 1-2 repetitions at $80-85 \%$ of the estimated $1 \mathrm{RM}$, resting for $5 \mathrm{~min}$, followed by testing the determined estimated 1RM weight. If the participant successfully completed the first 1RM attempt, they were instructed to rest for 4 min, then make another attempt after adding either 5-10 or 10-20 lbs, depending on the perceived difficulty of the previously completed $1 \mathrm{RM}$, as has been found to be effective by Hoeger and colleagues for testing a true 1 RM. ${ }^{132}$ This was continued until a true 1RM was established. The PI served as a spotter on all lifts to ensure participant safety while performing the barbell bench press, where proper form entailed feet maintaining contact with the floor and hips and head kept in contact with the 
bench. If participants broke proper form at any point during a 1RM attempt, the PI racked the weight and ceased any further testing, and used the previous successfully completed $1 \mathrm{RM}$ attempt in the data set.

\section{Maximal CMJ Height}

Maximal CMJ height was established using a commercially-available, vertical jump measuring device (Vertec; Sports Import Inc., Columbus, OH). The participants' maximum standing reach heights $(\mathrm{cm})$ were first be measured by the PI. Following, participants were guided through a warmup by performing 5 min of low-intensity cycling (60 revolutions $\cdot \mathrm{min}^{-1} ; 1.5 \mathrm{kp}$ ) on a stationary cycle ergometer (Monark Ergomedic $828 \mathrm{E}$; Monark Exercise AB, Vansbro, Sweden). Following, a brief dynamic warmup took place which consisted of ten BW squats and five CMJ performed at 50\% maximal intensity. Then, three trials of the maximal CMJ were completed, with 1 min of rest between each trial. Participants initiated the jump with both feet on the ground and descended into a countermovement before jumping vertically and swiping the Vertec measurement device at the highest possible point with the middle finger of the dominant hand, and then landed safely with flat feet and their knees slightly bent. Each jump height was recorded to the nearest $0.5 \%$. Participants were allowed three maximal CMJ attempts. If a participant showed progression in jump height on each consecutive attempt, they were allowed more attempts until they failed to bypass the previous attempt. Maximal CMJ heights were calculated by subtracting the respective jump heights by the participants' maximum standing reach heights $(\mathrm{cm})$. 


\section{$\underline{\text { Anthropometric Measures }}$}

To measure body height and weight, participants removed their shoes and only wore their shorts or under garments. Body heights were recorded using a stadiometer (Seca 213 Portable Stadiometer; Seca, Chino, CA). BW, FFM, and FM were measured using a Bod Pod as described by Antonio and colleagues in a similar study. ${ }^{133}$ Both pre- and posttreatment body measures were assessed in this fashion.

\section{$\underline{\text { Repeated Bench Press }}$}

Repetitions completed per set and total training volume (TTV; sets x repetitions) on three sets the submaximal (70\% of participants' 1RM) barbell bench press were assessed before and after the $1 \mathrm{wk}$ treatment period. Participants performed the barbell bench press exercise (three sets, maximal repetitions) at $70 \%$ of their previously determined $1 \mathrm{RM}$, with 2 min of rest and recovery between each set. The bench press warmups for visits 2 and 3 were identical to that of visit 1 with the progressing percentages adjusted for the $70 \%$ submaximal weight. A metronome was utilized ( 60 beats $\cdot \mathrm{min}^{-1}$ ) to control repetition tempo and to ensure all participants performed the exercise in the same fashion on all trials. Participants performed the exercise until complete muscle failure or until proper form (previously described) was broken, as determined by the PI. This was repeated until all three sets were complete. The PI served as the spotter on all lifts to ensure participant safety while performing the barbell bench press.

\section{$\underline{\text { Repeated CMJ }}$}

Repetitions completed per set and TTV were assessed on three sets of the repeated, submaximal ( $85 \%$ of participants' maximal vertical jump height) CMJ using the Vertec device before and after the $1 \mathrm{wk}$ treatment period. Using previously determined maximal 
CMJ height, participants completed as many consecutive submaximal CMJs as possible at $85 \%$ of their maximal CMJ height. The warmup for this test was identical to that of the maximal CMJ test during visit 1 , described above. The Vertec device was set to a height where the top horizontal measuring-stick was at $85 \%$ of the participants' maximal CMJ heights. The participants were instructed to only slightly touch the Vertec horizontal measuring sticks on each successful submaximal jump attempt. Each jump was interspersed by $3 \mathrm{~s}$ (recorded by the PI) upon landing from the previous jump to allow proper reset of participants' original jumping position and for the PI to quickly reset the moved horizontal measuring stick to its set position, if necessary. ${ }^{134}$ This was timed using a standard hand held digital stopwatch (Ultrak 495 Digital Stopwatch; CEI; Gardena, Ca). The PI was stationed on a latter placed next to the Vertec device to ensure participants successfully completed each submaximal CMJ and to allow for easy reset of the horizontal measuring stick after each attempt, if necessary. This continued until the participant could no longer jump at the desired height; the test was terminated after one unsuccessful repeated CMJ attempt. The number of successfully completed jumps at this height was recorded. Each set was separated by 2 min of rest/recovery. This took place for three trials before and after the $1 \mathrm{wk}$ treatment period.

\section{$\underline{\text { Data Analysis }}$}

Statistical analyses utilized the IBM Statistical Package for the Social Sciences (SPSS; IBM, Armonk, New York) software. Descriptive statistics (means and standard deviations) were calculated for age, height, BW, FFM, FM, 1RM bench press and maximal CMJ height. A series of one-way, repeated-measures ANOVAs were used to find any significant changes in body composition, bench press repetitions and number of 
submaximal CMJs from pre- to post-treatment on a per-set and TTV basis. A significance level was set at $p<0.05$. 


\section{CHAPTER FOUR: RESULTS}

Sixteen participants were initially recruited for this investigation. One participant dropped out due to personal health issues. Fifteen healthy, resistance trained males completed the study, whose baseline characteristics are listed in Table 4.1.

Table 4.1 Participant Baseline Characteristics $(n=15)$.

\begin{tabular}{|l|c|c|c|c|}
\hline & Minimum & Maximum & Mean & SD \\
\hline Age (yr) & 20 & 27 & 22.8 & 2.0 \\
\hline Height (cm) & 168.0 & 191.0 & 178.5 & 5.8 \\
\hline Body Weight (kg) & 70.1 & 105.4 & 81.6 & 9.9 \\
\hline 1 RM $^{\text {a }}$ Bench Press (kg) & 65.9 & 255.0 & 120.2 & 42.4 \\
\hline Max. $^{\text {b Vertical Jump Height }(\mathrm{cm})}$ & 51.2 & 87.6 & 70.1 & 9.8 \\
\hline
\end{tabular}

${ }^{\mathrm{a}}$ One-repetition maximum

${ }^{\mathrm{b}}$ Maximum vertical jump height

Dietary Supplement and Nutrition Intake

At the end of visits 2 and 3 participants were asked to recall their dietary intakes for any significant caloric changes and other dietary supplement intakes (if any). No participant reported changes in dietary intake at any point during the study. Every participant reported consuming meat daily, and all reported consuming a balanced diet with most of their caloric intakes coming from $\mathrm{CHO}$, followed by protein, then dietary fats. All participants reported adhering to the request to cease the consumption of alcohol $24 \mathrm{~h}$ prior to all testing sessions. 
All participants adhered to the study guidelines and refrained from using any dietary supplements other than the $\mathrm{CrHCl}$ treatment during the study (eg, whey protein and caffeine). Of the fifteen participants, all but one reported no use of any dietary supplements prior to the start of the study. These participants bypassed the 2 wk $\mathrm{Cr}$ washout period and began their visit 1s upon their earliest convenience. The one participant who reported using a pre-workout dietary supplement (with $\mathrm{Cr}$ and other nutrients) reported adhering to the 2 wk Cr washout phase before reporting to the laboratory for visit 1 . All fifteen participants reported adhering to the mixing and consumption protocols to ensure consistent absorption across participants. Further, all participants reported using the entirety of the distributed 1 wk supply of the $\mathrm{CrHCl}$ treatment and maintained proper consumption of the treatment during the periworkout period on training days and during the morning on rest-days, per study requirements. No participant reported stomach issues upon ingestion of the treatment.

\section{$\underline{\mathrm{CrHCl} \text { Purity }}$}

HPLC analysis revealed the $\mathrm{CrHCl}$ product to be $100 \%$ pure. Over a $10 \mathrm{~min}$ sample run time, there was a retention time of approximately 2 min and the absorption of the analyte was approximately 320 milli absorbance units (mAu) (Figure 4.1). Product purity of $100 \%$ assured that 1) participants were consuming a safe and pure product without any unknown substances and 2) any reported treatment effects, or lack of, could attributed to the $\mathrm{CrHCl}$ treatment with greater confidence.

\section{$\underline{\text { Repeated Bench Press }}$}

There was a significant main effect of time on bench press performance score, indicating that from pre- to post-intervention, participants' bench press performances 
improved across all three sets (Figure 4.1: $F(1,14)=106.4, p<0.005, \eta^{2}=0.88$ ).

Further, a significant main effect for set on bench press performance was found $(F(2,28)$ $\left.=268.3, p<0.005, \eta^{2}=0.95\right)$. Post-hoc Bonferroni analysis indicated that participants performed significantly better at later sets compared to earlier sets (eg, Set $3>$ Set $2>$ Set $1, p<0.005)$. A significant interaction between time and set on bench press was found $(F$ $\left.(2,28)=4.15, p=0.026, \eta^{2}=0.23\right)$, which indicates relatively larger improvement in bench press from pre- to post-intervention in Set 1 (Cohen's $d=0.71)$ and Set $3(d=$ $0.65)$, but smaller improvement for Set $2(d=0.39)$. This suggests that from pre- to postintervention, fatigue was better overcome when participants' upper-body muscles were unfatigued (Set 1) and at the end of the assessment, when their muscles were highly fatigued (Set 3). Bench press data are presented in Table 4.2.

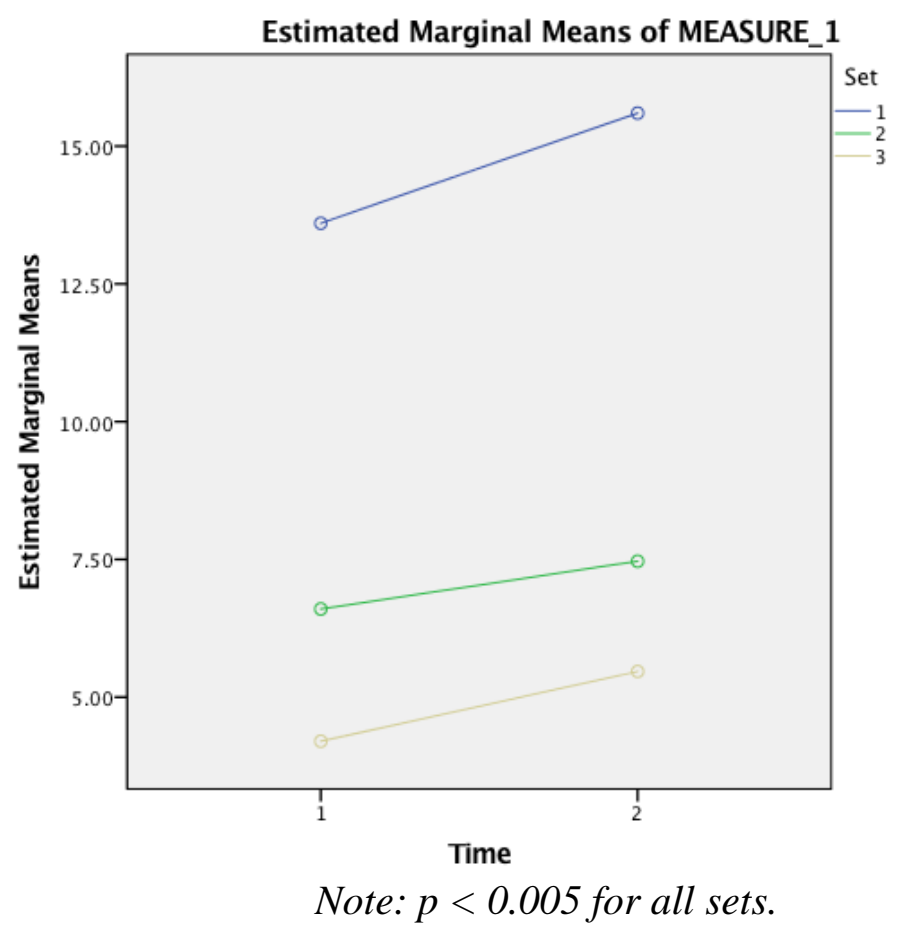

Figure 4.1 Effect for Time: Repeated Bench Press (Repetitions) 
Table 4.2 Participant Repeated Bench Press Characteristics (repetitions).

\begin{tabular}{|c|c|c|c|c|}
\hline & \multicolumn{2}{|c|}{ Pre-Intervention } & \multicolumn{2}{c|}{ Post-Intervention } \\
\cline { 2 - 5 } & Mean & SD & Mean & SD \\
\hline Set & 13.6 & 2.6 & $15.6^{*}$ & 3.0 \\
\hline Set & 6.6 & 2.3 & $7.5^{*}$ & 2.2 \\
2 & & & & \\
\hline Set & 4.2 & 1.8 & $5.5^{*}$ & 2.2 \\
\hline 3 & & & & \\
\hline
\end{tabular}

\section{$\underline{\text { Repeated CMJ }}$}

There was a significant effect for time on CMJ performance score, such that from pre- to post-intervention, participants' CMJ performances increased on all three sets (Figure 4.2: $\left.F(1,14)=55.61, p<0.005, \eta^{2}=0.80\right)$. Additionally, a significant main effect for set was found $\left(F(2,28)=27.5, p<0.005, \eta^{2}=0.66\right)$. Post-hoc Bonferroni results signified that participants performed significantly better at later sets compared to earlier sets (eg, Set $3>$ Set $2>$ Set $1, p<0.005)$. No significant interaction effect $(F(2$, 28) $\left.=0.96, p>0.05, \eta^{2}=0.06\right)$ was observed between time and set on the CMJ test, indicating that there were no significant improvements in $\mathrm{CMJ}$ from pre- to postintervention on any set (Set $1, d=0.41$; Set 2, $d=0.59$; Set 3, $d=0.63$ ). Data for the CMJ test are presented in Table 4.3. 


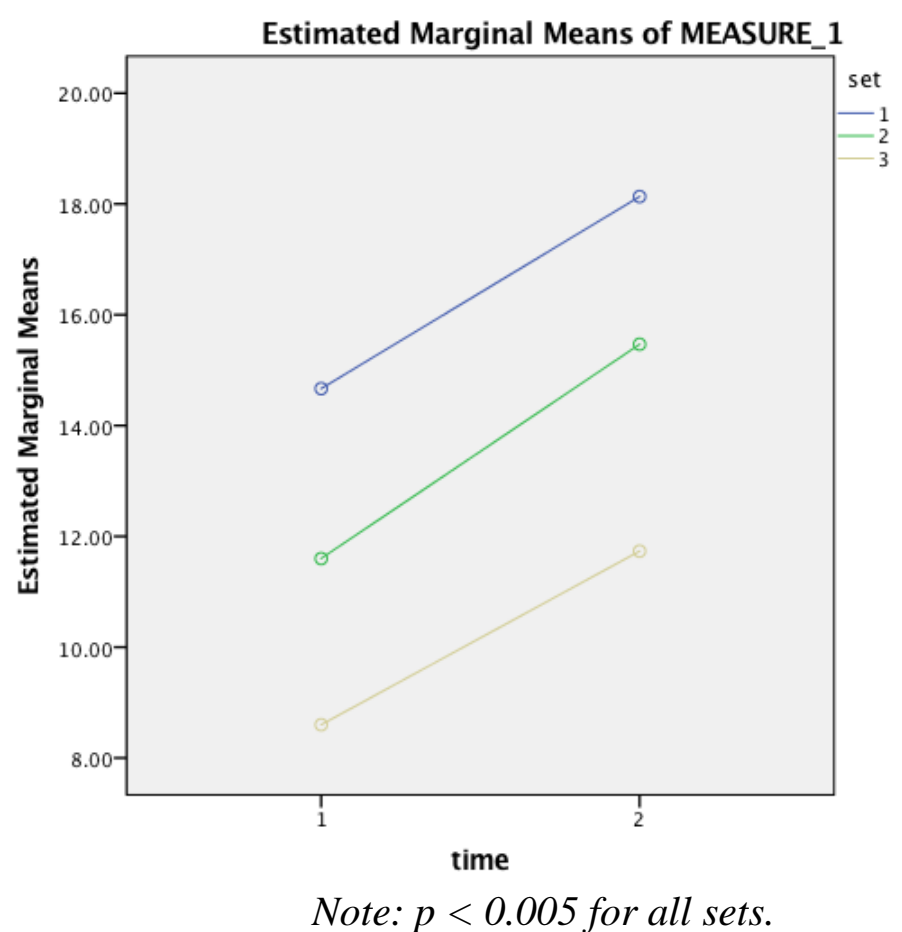

Figure 4.2 Effect for Time: Repeated CMJ (Repetitions)

Table 4.3 Participant Repeated CMJ Characteristics (repetitions).

\begin{tabular}{|c|c|c|c|c|}
\hline & \multicolumn{2}{|c|}{ Pre-Intervention } & \multicolumn{2}{|c|}{ Post-Intervention } \\
\hline & Mean & SD & Mean & SD \\
\hline $\begin{array}{c}\text { Set } \\
1\end{array}$ & 14.7 & 7.9 & $18.1^{*}$ & 8.3 \\
\hline $\begin{array}{c}\text { Set } \\
2\end{array}$ & 11.6 & 5.8 & $15.5^{*}$ & 7.2 \\
\hline $\begin{array}{c}\text { Set } \\
3\end{array}$ & 8.6 & 4.7 & $11.7^{*}$ & 5.0 \\
\hline
\end{tabular}




\section{$\underline{\text { Body Measures }}$}

There were no statistically significant changes in $\operatorname{FFM}(F(1,14)=3.06, p>0.05$, $\left.\eta^{2}=0.179\right)$ or FM $\left(F(1,14)=0.423, p>0.05, \eta^{2}=0.029\right)$ from pre- to post-treatment. Notably, however, there was a significant increase in BW from pre- to post-treatment $(F$ $\left.(1,14)=6.00, p<0.05, \eta^{2}=0.30\right)$. Data for all body composition outcomes are presented in Table 4.4 .

Table 4.4 Participant Body Composition Characteristics (kg).

\begin{tabular}{|l|c|c|c|c|}
\hline \multirow{2}{*}{} & \multicolumn{2}{|c|}{ Pre-Intervention } & \multicolumn{2}{c|}{ Post-Intervention } \\
\cline { 2 - 5 } & Mean & SD & Mean & SD \\
\hline BW & 81.6 & 9.9 & $82.2^{*}$ & 9.6 \\
\hline FFM $^{\mathrm{b}}$ & 70.4 & 8.0 & 71.3 & 7.9 \\
\hline FM $^{\mathrm{c}}$ & 11.3 & 3.1 & 10.9 & 3.8 \\
\hline
\end{tabular}

\footnotetext{
${ }^{a}$ Body weight

${ }^{\mathrm{b}}$ Fat-free mass

${ }^{\mathrm{c}}$ Fat mass
} 


\section{CHAPTER FIVE: DISCUSSION}

Consuming $\mathrm{CrH}_{2} \mathrm{O}$ as a dietary supplement with the intent of enhancing anaerobic muscular performance and body composition (eg, increasing FFM, decreasing FM) has shown consistent efficacy in the literature. Companies are producing alternative forms of $\mathrm{Cr}$, such as $\mathrm{CrHCl}$, to offset the various anecdotal reports of biological distress associated with consuming the relatively large amounts of $\mathrm{CrH}_{2} \mathrm{O}$ required to reap the ergogenic benefits. However, literature examining $\mathrm{CrHCl}$ in a human model is lacking and its efficacy remains unclear in augmenting muscular performance and favorable adaptations in body composition. Identifying the effect of oral $\mathrm{CrHCl}$ supplementation on submaximal, intermittent bouts of resistance exercise will help establish its effectiveness as a dietary supplement and will allow consumers to make educated decisions when purchasing Cr products.

In this study, measurements of completed repetitions on three sets of the barbell bench press and $\mathrm{CMJ}$ exercises were taken pre- and post-intervention in human participants. The results from the present study suggest that consuming $4 \mathrm{~g} \mathrm{CrHCl} \cdot \mathrm{d}^{-1}$ in the periworkout period for $7 \mathrm{~d}$ is beneficial for increasing repetitions on repeated bouts of submaximal bench press and CMJ exercises when taken to complete muscle failure. This supports the hypothesis that $7 \mathrm{~d}$ of $\mathrm{CrHCl}$ supplementation $\left(4 \mathrm{~g} \cdot \mathrm{d}^{-1}\right)$ taken in the periworkout period will increase repetitions on three repeated sets of the barbell bench press and CMJ exercises. Though participants were all previously well-versed in both performance assessments prior to the start of the study and practiced both tests during 
their Visit 1, it is important to acknowledge that learning effects or self-competition (trying to improve upon their baseline performances) may have contributed to these results. However, previous research examining repeated bouts of high intensity resistance exercise noted that learning effects from pre- to post-intervention are unlikely due to participants' previous resistance training experience $(\geq 1 \mathrm{y}) .{ }^{135}$ Thus, the lack of a control group in the present study likely was not an issue. Moreover, similar findings have been reported in the literature examining $\mathrm{CrH}_{2} \mathrm{O}$ supplementation and its effects on repeated bouts of submaximal exercise. ${ }^{23,136}$

A similar experiment investigated $\mathrm{CrH}_{2} \mathrm{O}$ supplementation for $7 \mathrm{~d}\left(25 \mathrm{~g} \cdot \mathrm{d}^{-1}\right)$ and its effects on five intermittent bouts of submaximal bench press (10 RM, failure) and jump squat exercises (30\% 1RM barbell back squat, ten repetitions), with each trial separated by 2 min rest. ${ }^{23}$ Peak power output (W) on all five sets of the jump squats and total training volume (TTV) on all five sets of the bench press were significantly enhanced $(p<0.05)$, with the highest numbers recorded on the first sets and progressively decreasing on the four subsequent sets. ${ }^{23}$ Though the experimental design (maximal repetitions at $85 \%$ maximal CMJ height) and performance measure (maximal repetitions) for the repeated jumps test was different in the present study, similar results were produced. The significant effect for time on repeated CMJ performance suggested a significant increase in completed repetitions across all three sets from pre- to postintervention. Thus, participants in the current study were also able to prolong the production of lower body peak power output and maintain their submaximal CMJ performances during post-intervention testing, as performance increased concurrently with increases in body mass. Bench press results in the present study were also similar, in 
that repetitions across sets were significantly enhanced from pre- to post-intervention. These results are likely attributed to more energy being derived from the enhanced phosphagen pool from the $\mathrm{CrHCl}$ treatment and a delayed transition into anaerobic glycolysis. ${ }^{44,46}$

An investigation of acute $\mathrm{CrH}_{2} \mathrm{O}$ supplementation $\left(20 \mathrm{~g} \cdot \mathrm{d}^{-1}, 5 \mathrm{~d}\right)$ on maximal repeated vertical jumping performance $(45 \mathrm{~s})$ reported significant $(p<0.05)$ enhancement in average jump height during the first $15 \mathrm{~s}(+7 \%)$ and $30 \mathrm{~s}(+12 \%)$, but not the final 15 s, when the energy-shift was likely being made to anaerobic glycolysis and aerobic metabolism. ${ }^{136}$ These results are similar to those in the present study where participants were likely able to produce greater muscular power as time and fatigue increased and continue reaching their $85 \%$ maximal CMJ heights, as evidenced in the post-intervention CMJ performance results, described above. In slightly longer $\mathrm{CrH}_{2} \mathrm{O}$ interventions (14 d), three pre-/post-trials of the $30 \mathrm{~s}$ maximal Wingate test were significantly enhanced $(+13 \%,+18 \%,+18 \%$, respectively, $p<0.05)$ as quantified by total anaerobic work and for submaximal bench press testing ( $28 \mathrm{~d} ; 70 \% 1 \mathrm{RM}$, one trial) for maximal repetitions $(+26 \%, p<0.05) .{ }^{47}$ Similarly, the present study saw upper and lower body increases in total anaerobic work capacity as seen by the increases in repetitions for the submaximal repeated CMJ and bench press exercises following the $\mathrm{Cr}$ treatment. However, the study at hand shows that similar performance results can be achieved in only $7 \mathrm{~d}$.

Results associating $\mathrm{CrH}_{2} \mathrm{O}$ supplementation with prolonged muscular power production during submaximal, intermittent bouts of exercise may be attributed to an increased quantity of $\mathrm{PCr}$ resynthesis due to increases in intramuscular $\mathrm{Cr}$ during the prescribed rest/recovery periods, and ultimately, an elevated $\mathrm{PCr}$ pool at the initiation of 
each successive bout of exercise. ${ }^{25}$ To maintain elevated power output during repeated maximal jumps, for example, requires constant ATP recycling via PCr hydrolysis at the myosin cross-bridge sites to maintain ideal myosin-head cycling with active sites located on the actin filament and elevated intramuscular $\mathrm{PCr}$ would enhance this. ${ }^{23,60}$ Brief periods of rest/recovery (eg, 2-5 min) allow for rapid PCr resynthesis which can be approximately $95 \%$ restored in 3-4 $\mathrm{min} .{ }^{9}$ Thus, repeated, intermittent performances on the submaximal bench press and CMJ exercises can be expected to be improved by $\mathrm{Cr}$ supplementation as demonstrated in this study.

Total intramuscular TCr seems to play a role in performance. ${ }^{19,25}$ Individuals with lower basal TCr concentrations (eg, non-supplemented individuals or vegetarians) experience more benefit as they tend to have a greater relative and absolute increase in $\mathrm{TCr}$ pools upon supplementation (+ 20\%) and the extent to which intramuscular $\mathrm{TCr}$ pools increase is related to the enhancement in muscular performance. ${ }^{30} \mathrm{With} \mathrm{TCr}$ retention so important for reaping ergogenic benefits from $\mathrm{Cr}$ supplementation, those consuming $\mathrm{Cr}$ would ideally increase their intramuscular $\mathrm{TCr}$ pools from the average $120-140 \mathrm{mmol} \cdot \mathrm{kg}^{-1}(\mathrm{DM})$ to the known upper limit of $150-155 \mathrm{mmol} \cdot \mathrm{kg}^{-1}(\mathrm{DM}){ }^{60}$

However, publications examining $\mathrm{CrHCl}$ supplementation and retention have yet to be conducted in a human model, making it unclear as to the appropriate dose and timing needed to properly increase intramuscular TCr levels. This may explain why there have been disparate results in the literature across the few available $\mathrm{CrHCl}$ training studies. Possible discrepancies in the literature may be attributed to factors, such as varied dosing of the $\mathrm{CrHCl}$ treatments, length of the treatment periods, or testing protocols not fully utilizing the phosphagen energy system. ${ }^{26,30,60}$ One study that 
examined the 4 wk effects of a high dose $\left(5 \mathrm{~g} \cdot \mathrm{d}^{-1}\right)$ or low dose $\left(1.5 \mathrm{~g} \cdot \mathrm{d}^{-1}\right)$ of $\mathrm{CrHCl}$ versus $5 \mathrm{~g} \cdot \mathrm{d}^{-1} \mathrm{CrH}_{2} \mathrm{O}$ and a $\mathrm{Pl}$ group reported increases in $1 \mathrm{RM}$ leg press in all groups but only 1RM bench press in the low $\mathrm{CrHCl}$ group. ${ }^{75}$ Participants in this study were asked to refrain from all PA 4 wk prior to the start of the study which may have played a role in the reported strength increases. Another study had participants consume a single dose $\left(0.033 \mathrm{~g} \cdot \mathrm{kg}^{-1}\right)$ of $\mathrm{CrHCl}, 30 \mathrm{~min}$ prior to pre- and post-testing on five repeated sets of the bench press and leg press with $75 \mathrm{~s}$ rest between each set. ${ }^{128}$ It was found that TTV for men and women in the leg press significantly improved (men: $+12.9 \%, p=0.03$; women; $+32.7 \%, p=0.004$ ) for all groups including the Pl while TTV on the bench press showed no significant improvements in any group. ${ }^{128}$ This is likely due to only a single dose of $\mathrm{CrHCl}$ not being enough to maximize $\mathrm{TCr}$ stores in the muscle cells. In addition, participants were asked to refrain from exercise between the control and experimental trials although exercised muscle tissue better takes up and stores circulating $\mathrm{Cr}$ than unexercised muscle tissue. It is also possible that the $75 \mathrm{~s}$ rest periods were not sufficient enough for PCr resynthesis between exercise bouts. ${ }^{60} \mathrm{~A}$ third investigation looked at $6 \mathrm{~d} \mathrm{CrHCl}$ supplementation $\left(750 \mathrm{mg} \cdot \mathrm{d}^{-1}\right.$, twice daily) on $1 \mathrm{RM}$ performances on the bench press, back squat, and deadlift exercises and found no significant changes posttreatment. ${ }^{129}$ Because $1 \mathrm{RM}$ attempts do not rely on phosphate sources other than already available ATP, increased intramuscular TCr through supplementation without resistancetraining for only $6 \mathrm{~d}$ would not likely instigate the necessary training effects necessary to augment significant gains in maximal muscular strength. ${ }^{60}$

In an attempt to build on the aforementioned literature and eliminate discrepancies in results, the present study took each potential flaw in the aforesaid 
research designs and addressed them accordingly. First, participants were asked to maintain their usual resistance training regimens (minimum $3 \mathrm{~d} \cdot \mathrm{wk}^{-1}$ ) before and throughout the $\mathrm{Cr}$ intervention period. This would help eliminate performance improvements being attributed to unexercised muscle tissue undergoing a resistance training and $\mathrm{Cr}$ intervention, as opposed to previously resistance trained muscle tissue continuing to resistance train while undergoing a $\mathrm{Cr}$ intervention. Further, a single dose of Cr taken 30 min prior to a maximal, weight-bearing performance assessment would not likely elevate intramuscular TCr levels enough to provide a difference in performance, especially when asked to refrain from resistance training leading up to the assessment. Thus, the present study had participants resistance train while supplementing with $4 \mathrm{~g}$ of $\mathrm{CrHCl}$ in the periworkout period around their respective resistance training workouts, over a $7 \mathrm{~d}$ span, which would likely better increase their skeletal muscle $\mathrm{TCr}$ stores and improve their intermittent, submaximal resistance training performances. Additionally, rest periods under 2 min, as discussed previously, are not sufficient enough to allow sufficient $\mathrm{PCr}$ resynthesis following a trial of maximal-effort PA. ${ }^{9}$ Therefore, the study at hand utilized 2 min rest periods between testing trials which would allow sufficient PCr resynthesis by utilizing ATP from oxidative metabolism and the anaerobic metabolism of hexose monophosphates (accumulated during intense exercise) to pyruvate before the successive testing trials. ${ }^{9}$ Lastly, studies testing pre- and post-1RM after an acute $\mathrm{Cr}$ treatment period should not expect to see significant improvements, as such lifts tend to use energy from readily available phosphates, namely ATP. ${ }^{30}$ Thus, the current study designed a performance protocol that utilized exercises that rely primarily on the ATP-PCr energy system and would more likely benefit from $\mathrm{Cr}$ supplementation. 
Regardless, there are still some limitations in the design of this study, which will be discussed at the end of this section.

In this investigation, FFM and FM saw no statistically significant changes from pre- to post-intervention ( $p>0.05$ for both). However, BW was significantly increased from pre- to post-intervention $\left(F(1,14)=6.00, p<0.05, \eta^{2}=0.30\right)$. Mean bodyweight in the present study increased approximately $0.6 \mathrm{~kg}$. Many $\mathrm{CrH}_{2} \mathrm{O}$ studies with acute treatment periods (6-14 d) have reported similar increases in body mass, ranging from 0.5-2.0 kg. ${ }^{23,25,44,47,61,80,81,114,137}$ As indicated by decreases in urinary volume upon $\mathrm{Cr}$ supplementation, this may be mostly attributed to increased retention of body water. ${ }^{119}$ This may be due to the fact that increased $\mathrm{Cr}$ content in the muscle cell increases osmotic pressure, which moves $\mathrm{H}_{2} \mathrm{O}$ into the cell and retains it, leading to weight gain. ${ }^{70}$ It is important to note that no participants in the present study reported any biologic distress during the intervention period. Further, consuming $\mathrm{CrH}_{2} \mathrm{O}$ in the periworkout period has been found to increase FFM while decreasing FM, which may help further influence changes in body composition. ${ }^{133}$ Thus, the study at hand had participants split their daily $\mathrm{CrHCl}$ doses pre- and post-workout on days where they resistance trained.

These results suggest that supplementing with $4 \mathrm{~g}$ of $\mathrm{CrHCl}$ over a $7 \mathrm{~d}$ period may benefit those who seek to improve muscular performances during intermittent, submaximal PAs and avoid possible biologic distress associated with $\mathrm{CrH}_{2} \mathrm{O}$ supplementation at such high doses. Thus, supplementing with $\mathrm{CrH}_{2} \mathrm{O}$ is approximately \$0.29 cheaper per day to supplement with compared to $\mathrm{CrHCl}$. This may have more specific implications for those other than just healthy men who resistance train. For instance, the National Football League Scouting Combine utilizes a $225 \mathrm{lb}(\sim 102.3 \mathrm{~kg})$ 
bench press test (maximal repetitions to fatigue) to assess upper body muscular strength and endurance. A potential recruit may be $1 \mathrm{wk}$ out from the Scouting Combine and still need to improve on the number of repetitions he can perform during the submaximal bench press test. With this knowledge, his trainer may have him supplement with $4 \mathrm{~g}$ of $\mathrm{CrHCl} \cdot \mathrm{d}^{-1}$ around his workouts, for $7 \mathrm{~d}$, with the intent of increasing his intramuscular $\mathrm{TCr}$ stores, and thus utilizing more phosphate energy sources before transitioning to anaerobic glycolysis. This would allow for more completed repetitions on the submaximal bench press test.

Additionally, players who participate in sports that require repeated bouts of maximal vertical jumping, such as volleyball, may benefit from these findings. The ability to sustain near-maximal CMJ height may allow players to compete at higher levels through the duration a given match. Coaches can therefore utilize these results and have their players practice and resistance train their lower extremities while supplementing with $4 \mathrm{~g}$ of $\mathrm{CrHCl} \cdot \mathrm{d}^{-1}$ during the week before a match. With an increased $\mathrm{TCr}$ pool in the lower extremities, the athletes should expect to maintain submaximal CMJ performances for longer periods of time during a given match.

Regardless of the sport, to maximize the benefits of $\mathrm{CrHCl}$ supplementation, the PA one wishes to improve upon should stress the phosphagen energy system and should have brief periods of rest/recovery between bouts, ranging from 2-5 min. This has proven to be an effective alternative to supplementing with high doses of $\mathrm{CrH}_{2} \mathrm{O}$.

However, a $500 \mathrm{~g}$ bottle of $\mathrm{CrH}_{2} \mathrm{O}$ has a retail cost of $\$ 14.99$ (USD; $20 \mathrm{~g} \cdot \mathrm{d}^{-1}=$ $\$ 0.60 \cdot \mathrm{d}^{-1}$ ) while a $135 \mathrm{~g}$ bottle of $\mathrm{CrHCl}$ sells at retail for approximately $\$ 30.00$ (USD; 4 $\left.\mathrm{g} \cdot \mathrm{d}^{-1}=\$ 0.89 \cdot \mathrm{d}^{-1}\right) \cdot{ }^{86}$ 


\section{$\underline{\text { Limitations and Future Research }}$}

There were some limitations in the present study. One major limitation of the current study was the small sample size. Data from 15 participants is not enough to generalize the results to larger populations outside of a cohort of healthy, resistance trained men. Additionally, the brief, $7 \mathrm{~d}$ treatment period may not have been sufficient for some individuals as they may respond slower to Cr supplementation (delayed uptake of intramuscular $\mathrm{TCr}$ ) or may not respond at all ( $\mathrm{Cr}$ treatment has no influence on intramuscular TCr content) and this was not assessed in this study. ${ }^{26}$ Further, muscle biopsy techniques or tracer methodologies were not used to quantify intramuscular $\mathrm{TCr}$ content pre- and post-intervention, so it cannot be concluded that the improvements in performance were a direct result of the $\mathrm{Cr}$ treatment. Moreover, although all participants reported consuming their normal diets throughout the intervention, only general diet information was collected and specific caloric intakes, especially from meat, were not tracked throughout the intervention. Differences in energy intake, especially from $\mathrm{Cr}$ dense meat, could have further increased participants' intramuscular TCr stores and influenced performance results. Lastly, this was an open trial as participants were not blinded to the $\mathrm{CrHCl}$ treatment, which may be a cause for bias.

Follow up studies should longitudinally investigate $\mathrm{CrHCl}$ supplementation in resistance trained men and women with a greater sample size and investigate the longterm effects on performance and body composition. Further, $\mathrm{CrHCl}$ supplementation among older populations of both sexes should be examined for TCr retention, body composition and anaerobic performance outcomes to further assess its effects on other populations. Moreover, basal and post-intervention intramuscular TCr content should be 
measured via biopsy techniques or tracer methodologies to measure the retention effects of $\mathrm{CrHCl}$ in comparison to $\mathrm{CrH}_{2} \mathrm{O}$, and assess the correlation between retention level and performance changes. Caloric intake, especially meat intake, should be controlled to ensure the consumption of meat products remains consistent throughout the treatment period. Lastly, participants should be blinded to the treatment and the $\mathrm{CrHCl}$ group should be compared against a $\mathrm{CrH}_{2} \mathrm{O}$ group and a $\mathrm{Pl}$ group to avoid potential bias. $\underline{\text { Conclusion }}$

In conclusion, supplementation with $4 \mathrm{~g}$ of $\mathrm{CrHCl}$ for $7 \mathrm{~d}$ in healthy, resistancetrained men significantly increases the number of repetitions performed during intermittent bouts of submaximal bench press and CMJ exercises and body weight. 


\section{REFERENCES}

1. Caspersen CJ, Powell KE, Christenson GM. Physical activity, exercise, and physical fitness: definitions and distinctions for health-related research. Public Health Reports. 1985 Mar-Apr 1985;100(2):126-131.

2. Massidda M, Cugusi L, Mathieu A. Physical activity levels and health-related quality of life in young Italian population. Journal of Sports Medicine and Physiological Fitness. May 2015;55(5):506-512.

3. (Ed.) ACoSM. ACSM's health-related physical fitness assessment manual. Lippincott Williams \& Wilkins; 2013.

4. Clarke HH. Application of measurement to health and physical education. 4 ed. Englewood Cliffs, NJ: Prentice-Hall; 1976.

5. Adams G, Beam W. Exercise Physiology Laboratory Manual. 5 ed. New York, NY: McGraw-Hill; 2008.

6. Hultman E, Sjöholm H. Energy metabolism and contraction force of human skeletal muscle in situ during electrical stimulation. Journal of Physiology. Dec $1983 ; 345: 525-532$.

7. Katz A, Sahlin K, Henriksson J. Muscle ATP turnover rate during isometric contraction in humans. Journal of Applied Physiology (1985). Jun 1986;60(6):1839-1842. 
8. Agteresch HJ, Dagnelie PC, van den Berg JW, Wilson JH. Adenosine triphosphate: established and potential clinical applications. Drugs. Aug $1999 ; 58(2): 211-232$.

9. Harris RC, Edwards RH, Hultman E, Nordesjö LO, Nylind B, Sahlin K. The time course of phosphorylcreatine resynthesis during recovery of the quadriceps muscle in man. Pflugers Archives. Dec 1976;367(2):137-142.

10. Westerblad H, Bruton JD, Katz A. Skeletal muscle: energy metabolism, fiber types, fatigue and adaptability. Experimental Cell Research. Nov 2010;316(18):3093-3099.

11. Andres R, Widmer H, Hornemann T, Saks V, Agarkova I, Schlattner U. The Phosphocreatine Circuit: Molecular and Cellular Physiology of Creatine Kinases, Sensitivity to Free Radicals, and Enhancement by Creatine Supplementation. Molecular System Bioenergetics: Energy for Life. 2007.

12. Andres L, Sacheck J, Tapia S. A Review of Creatine Supplementation: Side Effects and Improvements in Athletic Performance. Nutrition In Clinical Care. 1999;2(2):73-81.

13. Di Prampero PE, Margaria R. Mechanical efficiency of phosphagen (ATP+CP) splitting and its speed of resynthesis. Pflugers Archives. 1969;308(3):197-202.

14. Hargreaves M. Skeletal muscle metabolism during exercise in humans. Clinical \& Experimental Pharmacology \& Physiology. 2000;27(3):225.

15. Sahlin K, Tonkonogi M, Söderlund K. Energy supply and muscle fatigue in humans. Acta Physiologica Scandanavia. Mar 1998;162(3):261-266. 
16. Karatzaferi C, de Haan A, van Mechelen W, Sargeant AJ. Metabolism changes in single human fibres during brief maximal exercise. Experimental Physiology. May 2001;86(3):411-415.

17. Sahlin K. Principles of Exercise Biochemistry. Vol 46. 3 ed. Switzerland: Karger; 2004.

18. Demant $\mathrm{T}$, Rhodes E. Effects of creatine supplementation on exercise performance. Sports Medicine. 1999;28(1):49-60.

19. Casey A, Constantin-Teodosiu D, Howell S, Hultman E, Greenhaff PL. Creatine ingestion favorably affects performance and muscle metabolism during maximal exercise in humans. American Journal of Physiology. Jul 1996;271(1 Pt 1):E3137.

20. Gaitanos G, Williams C, Boobis L, Brooks S. Human muscle metabolism during intermittent maximal exercise. Journal of Applied Physiology. 1993;75(2):712719.

21. Crim M, Calloway D, Margen S. Creatine metabolism in men: creatine pool size and turnover in relation to creatine intake. Journal of Nutrition. 1976;105:428438.

22. McCardle W, Katch F, Katch V. Exercise Physiology: Nutrition, Energy, and Human Performance. 8 ed. Baltimore: Wolters Kluwer Health; 2015.

23. Volek JS, Kraemer WJ, Bush JA, et al. Creatine supplementation enhances muscular performance during high-intensity resistance exercise. Journal of American Diet Association. Jul 1997;97(7):765-770. 
24. Boobis L, Williams C, Cheetham M, Wootton S. Metabolic aspects of fatigue during sprinting. Exercise Benefits, Limits and Adaptations. 1987:116-143.

25. Greenhaff PL, Bodin K, Soderlund K, Hultman E. Effect of oral creatine supplementation on skeletal muscle phosphocreatine resynthesis. American Journal of Physiology. May 1994;266(5 Pt 1):E725-730.

26. Terjung RL, Clarkson P, Eichner ER, et al. American College of Sports Medicine roundtable. The physiological and health effects of oral creatine supplementation. Medicine and Science in Sports and Exercise. Mar 2000;32(3):706-717.

27. Bloch K, Schoenheimer R. The biological precursors of creatine. Journal of Biological Chemistry. 1941;138:167-194.

28. Walker J. Creatine: biosynthesis, regulation and function. Advances in Enzymology and Related Areas in Molecular Biology. 1979;50:177-242.

29. Balsom PD, Söderlund K, Ekblom B. Creatine in humans with special reference to creatine supplementation. Sports Medicine. Oct 1994;18(4):268-280.

30. Volek J, Kraemer W. Creatine supplementation: its effect on human muscular performance and body composition. The Journal of Strength \& Conditioning Research. 1996;10(3):200-210.

31. Yasuda M, Sugahara K, Zhang J, et al. Simultaneous determination of creatinine, creatine, and guanidinoacetic acid in human serum and urine using liquid chromatography-atmospheric pressure chemical ionization mass spectrometry. Analytical Biochemistry. 1997;253:231-235. 
32. Hoberman HD, Sims EA, Peters JH. Creatine and creatinine metabolism in the normal male adult studied with the aid of isotopic nitrogen. Journal of Biological Chemistry. Jan 1948;172(1):45-58.

33. Picou D, Reeds PJ, Jackson A, Poulter N. The measurement of muscle mass in children using [15N]creatine. Pediatric Research. Mar 1976;10(3):184-188.

34. Poortmans J. Principles of Exercise Biochemistry. Vol 46.3 ed. Switzerland: Karger; 2004.

35. Delanghe J, De Slypere JP, De Buyzere M, Robbrecht J, Wieme R, Vermeulen A. Normal reference values for creatine, creatinine, and carnitine are lower in vegetarians. Clinical Chemistry. Aug 1989;35(8):1802-1803.

36. Ropero-Miller JD, Paget-Wilkes H, Doering PL, Goldberger BA. Effect of oral creatine supplementation on random urine creatinine, $\mathrm{pH}$, and specific gravity measurements. Clinical Chemistry. Feb 2000;46(2):295-297.

37. Harris RC, Lowe JA, Warnes K, Orme CE. The concentration of creatine in meat, offal and commercial dog food. Research in Vetinerary Science. 1997 Jan-Feb 1997;62(1):58-62.

38. Purchas RW, Rutherfurd SM, Pearce PD, Vather R, Wilkinson BH. Concentrations in beef and lamb of taurine, carnosine, coenzyme Q(10), and creatine. Meat Science. Mar 2004;66(3):629-637.

39. Knapik JJ, Steelman RA, Hoedebecke SS, Austin KG, Farina EK, Lieberman HR. Prevalence of Dietary Supplement Use by Athletes: Systematic Review and MetaAnalysis. Sports Medicine. Jan 2016;46(1):103-123. 
40. Pittas G, Hazell MD, Simpson EJ, Greenhaff PL. Optimization of insulinmediated creatine retention during creatine feeding in humans. Journal of Sports Science. Jan 2010;28(1):67-74.

41. Harris R, Sale C, Delves S. Modification Of The Ergogenic Effects Of Creatine Loading By Caffeine. Medicine \& Science in Sports \& Exercise. 2005;37.

42. Harris RC, Söderlund K, Hultman E. Elevation of creatine in resting and exercised muscle of normal subjects by creatine supplementation. Clinical Science (London). Sep 1992;83(3):367-374.

43. Harris R, Viru M, Greenhaff P, Hultman E. The effect of oral creatine supplementation on running performance during maximal short term exercise in man. Journal of Physiology-London Then Cambridge. 1993;1(467):74.

44. Balsom P, Ekblom B, Söerlund K, Sjödln B, Hultman E. Creatine supplementation and dynamic high-intensity intermittent exercise. Scandinavian Journal of Medicine \& Science in Sports. 1993;3(3):143-149.

45. Birch R, Noble D, Greenhaff PL. The influence of dietary creatine supplementation on performance during repeated bouts of maximal isokinetic cycling in man. European Journal of Applied Physiology and Occupational Physiology. 1994;69(3):268-276.

46. Söderlund K, Balsom P, Ekblom B. Creatine supplementation and high intensity exercise: influence on performance and muscle metabolism. Clinical Science. 1994;87(s1):120-121.

47. Earnest CP, Snell PG, Rodriguez R, Almada AL, Mitchell TL. The effect of creatine monohydrate ingestion on anaerobic power indices, muscular strength 
and body composition. Acta Physiologica Scandanavia. Feb 1995;153(2):207209.

48. Greenhaff PL, Casey A, Short AH, Harris R, Soderlund K, Hultman E. Influence of oral creatine supplementation of muscle torque during repeated bouts of maximal voluntary exercise in man. Clinical Science (London). May 1993;84(5):565-571.

49. Navratil T, Kohlikova E, Petr M, et al. Contribution to explanation of the effect of supplemented creatine in human metabolism. Food Chemistry. 2009;112(2):500506.

50. Francaux M, Poortmans JR. Effects of training and creatine supplement on muscle strength and body mass. European Journal of Applied Physiology and Occupational Physiology. Jul 1999;80(2):165-168.

51. Stout J, Eckerson J, Ebersole K, et al. Effect of creatine loading on neuromuscular fatigue threshold. Journal of Applied Physiology (1985). Jan 2000;88(1):109-112.

52. Tarnopolsky MA, Parise G, Yardley NJ, Ballantyne CS, Olatinji S, Phillips SM. Creatine-dextrose and protein-dextrose induce similar strength gains during training. Medicine and Science in Sports and Exercise. Dec 2001;33(12):20442052.

53. Burd NA, West DW, Staples AW, et al. Low-load high volume resistance exercise stimulates muscle protein synthesis more than high-load low volume resistance exercise in young men. PLoS One. Aug 2010;5(8):e12033.

54. Ahtiainen JP, Pakarinen A, Alen M, Kraemer WJ, Häkkinen K. Muscle hypertrophy, hormonal adaptations and strength development during strength 
training in strength-trained and untrained men. European Journal of Applied Physiology. Aug 2003;89(6):555-563.

55. Goto K, Nagasawa M, Yanagisawa O, Kizuka T, Ishii N, Takamatsu K. Muscular adaptations to combinations of high- and low-intensity resistance exercises. Journal of Strength and Conditioning Research. Nov 2004;18(4):730-737.

56. Phillips SM, Tipton KD, Aarsland A, Wolf SE, Wolfe RR. Mixed muscle protein synthesis and breakdown after resistance exercise in humans. Am J Physiol. Jul 1997;273(1 Pt 1):E99-107.

57. Rawson ES, Clarkson PM. Acute creatine supplementation in older men. International Journal of Sports Medicine. Jan 2000;21(1):71-75.

58. Rawson ES, Wehnert ML, Clarkson PM. Effects of 30 days of creatine ingestion in older men. European Journal of Applied Physiology and Occupational Physiology. Jul 1999;80(2):139-144.

59. Vandenberghe K, Van Hecke M, Van Leemputte F, Vanstapel F, Hespel P. Phosphocreatine resynthesis is not affected by creatine loading. Medicine and Science in Sports and Exercise. 1999;36:236-242.

60. Kraemer WJ, Volek JS. Creatine supplementation. Its role in human performance. Clinical Sports Medicine. Jul 1999;18(3):651-666, ix.

61. Volek JS, Duncan ND, Mazzetti SA, et al. Performance and muscle fiber adaptations to creatine supplementation and heavy resistance training. Medicine and Science in Sports and Exercise. Aug 1999;31(8):1147-1156.

62. Williams M, Kreider R, Branch J. Creatine: The Power Supplement. Champaign, IL: Human Kinetics; 1999. 
63. Pearson D, Hamby D, Russel W, Harris T. Long-term effects of creatine monohydrate on strength and power. Journal of Strength and Conditioning Research. 1999;13:187-192.

64. Antonio J. Creatine Loading and Maintenance Dosing. Strength \& Conditioning Journal. 2004;26(1):26-27.

65. Poortmans J, Francaux M. Long-term oral creatine supplementation does not impair renal function in healthy athletes. Medicine and Science in Sports and Exercise. 1999;31:1108-1110.

66. Mihic S, Macdonald J, McKenzie S, Tarnopolsky M. Acute creatine loading increases fat-free mass, but does not affect blood pressure, plasma creatinine nor CK activity. Medicine and Science in Sports and Exercise. 2000;32(2):291-296.

67. Peeters B, Lantz C, Mayhew J. Effect of oral creatine monohydrate and creatine phosphate supplementation on maximal strength indices, body composition, and blood pressure. Journal of Strength and Conditioning Research. 1999;13:3-9.

68. Vandebuerie F, Vanden Eynde B, Vandenberghe K, Hespel P. Effect of creatine loading on endurance capacity and sprint power in cyclists. International Journal of Sports Medicine. Oct 1998;19(7):490-495.

69. Gufford BT, Ezell EL, Robinson DH, et al. pH-dependent stability of creatine ethyl ester: relevance to oral absorption. Journal of Dietary Supplements. Sep $2013 ; 10(3): 241-251$.

70. Powers ME, Arnold BL, Weltman AL, et al. Creatine Supplementation Increases Total Body Water Without Altering Fluid Distribution. Journal of Athletic Training. Mar 2003;38(1):44-50. 
71. Ziegenfuss T, Lowery M, Lemon W. Acute fluid volume changes in men during three days of creatine supplementation. Journal of Exercise Physiology. $1998 ; 1(3): 1-4$.

72. Groeneveld GJ, Beijer C, Veldink JH, Kalmijn S, Wokke JH, van den Berg LH. Few adverse effects of long-term creatine supplementation in a placebo-controlled trial. International Journal of Sports Medicine. May 2005;26(4):307-313.

73. Graham AS, Hatton RC. Creatine: a review of efficacy and safety. Journal of American Pharmacists Association (Washington). 1999 Nov-Dec 1999;39(6):803810; quiz 875-807.

74. Ostojic SM, Ahmetovic Z. Gastrointestinal distress after creatine supplementation in athletes: are side effects dose dependent? Research in Sports Medicine. 2008;16(1):15-22.

75. de França E, Avelar B, Yoshioka C, et al. Creatine $\mathrm{HCl}$ and Creatine Monohydrate Improve Strength but Only Creatine $\mathrm{HCl}$ Induced Changes on Body Composition in Recreational Weightlifters. Food and Nutrition Sciences. 2015;6(17):1624.

76. Miller D, Vennerstrom J, Faulkner M, Inventors; Board of Regents of the University of Nebraska, NE, assignee. <invention-title lang="EN">Creatine oral supplementation using creatine hydrochloride salt</invention-title>. 2009.

77. Dash A, Miller D, Huai-Yan H, Carnazzo J, Stout J. Evaluation of creatine transport using Caco - 2 monolayers as an in vitro model for intestinal absorption. Journal of Pharmaceutical Sciences. 2001;90(10):1593-1598. 
78. Steenge GR, Simpson EJ, Greenhaff PL. Protein- and carbohydrate-induced augmentation of whole body creatine retention in humans. Journal of Applied Physiology (1985). Sep 2000;89(3):1165-1171.

79. Preen D, Dawson B, Goodman C, Beilby J, Ching S. Creatine supplementation: a comparison of loading and maintenance protocols on creatine uptake by human skeletal muscle. International Journal of Sport Nutrition and Exercise Metabolism. Mar 2003;13(1):97-111.

80. Green AL, Simpson EJ, Littlewood JJ, Macdonald IA, Greenhaff PL. Carbohydrate ingestion augments creatine retention during creatine feeding in humans. Acta Physiologica Scandanavia. Oct 1996;158(2):195-202.

81. Green AL, Hultman E, Macdonald IA, Sewell DA, Greenhaff PL. Carbohydrate ingestion augments skeletal muscle creatine accumulation during creatine supplementation in humans. American Journal of Physiology. Nov 1996;271(5 Pt 1):E821-826.

82. Barnett C, Hinds M, Jenkins DG. Effects of oral creatine supplementation on multiple sprint cycle performance. Australian Journal of Science and Medicine in Sport. Mar 1996;28(1):35-39.

83. Steenge GR, Lambourne J, Casey A, Macdonald IA, Greenhaff PL. Stimulatory effect of insulin on creatine accumulation in human skeletal muscle. American Journal of Physiology. Dec 1998;275(6 Pt 1):E974-979.

84. Odoom JE, Kemp GJ, Radda GK. The regulation of total creatine content in a myoblast cell line. Molecular Cell Biochemistry. May 1996;158(2):179-188. 
85. Chanutin A, Guy L. The fate of creatine when administered to man. Journal of Biological Chemistry. 1926;67:29-41.

86. NutraBio. Creatine Products. 2017; NutraBio Creatine Product Price Comparison: $\mathrm{HCl}$ vs Monohydrate. Available at: http://www.nutrabio.com/category/creatine/. Accessed February 26, 2017, 2017.

87. Gufford BT, Sriraghavan K, Miller NJ, et al. Physicochemical characterization of creatine N-methylguanidinium salts. Journal of Dietary Supplements. Sep 2010;7(3):240-252.

88. Koshland DE. Application of a Theory of Enzyme Specificity to Protein Synthesis. Proceedings of the National Academy of Sciences U S A. Feb 1958;44(2):98-104.

89. Koshland D. The key-lock theory and the induced fit theory. Angewandte Chemie International Edition in English. 1995;33(23-24):2375-2378.

90. Marieb E, Hoehn K. Human Anatomy and Physiology. Second Custom Edition for Skyline College ed. Boston, MA: Pearson Learning Solutions; 2013.

91. Cordes E. Mechanism and catalysis for the hydrolysis of acetals, ketals, and ortho esters. Progress in Physical Organic Chemistry. 1967;4:1-44.

92. Edström L, Hultman E, Sahlin K, Sjöholm H. The contents of high-energy phosphates in different fibre types in skeletal muscles from rat, guinea-pig and man. Journal of Physiology. Nov 1982;332:47-58.

93. Alberty RA. Effect of $\mathrm{pH}$ and metal ion concentration on the equilibrium hydrolysis of adenosine triphosphate to adenosine diphosphate. Journal of Biological Chemistry. Apr 1968;243(7):1337-1343. 
94. Wallimann T, Wyss M, Brdiczka D, Nicolay K, Eppenberger H. Intracellular compartmentation, structure and function of creatine kinase isoenzymes in tissues with high and fluctuating energy demands: the phosphocreatine circuit for cellular energy homeostasis. Biochemical Journal. 1992;281(pt 1)(21).

95. Dudley GA, Terjung RL. Influence of acidosis on AMP deaminase activity in contracting fast-twitch muscle. American Journal of Physiology. Jan 1985;248(1 Pt 1):C43-50.

96. Dudley GA, Terjung RL. Influence of aerobic metabolism on IMP accumulation in fast-twitch muscle. American Journal of Physiology. Jan 1985;248(1 Pt 1):C3742.

97. Meyer RA, Terjung RL. AMP deamination and IMP reamination in working skeletal muscle. American Journal of Physiology. Jul 1980;239(1):C32-38.

98. Katz A, Broberg S, Sahlin K, Wahren J. Muscle ammonia and amino acid metabolism during dynamic exercise in man. Clinical Physiology. Aug 1986;6(4):365-379.

99. Jacobs I, Tesch PA, Bar-Or O, Karlsson J, Dotan R. Lactate in human skeletal muscle after 10 and $30 \mathrm{~s}$ of supramaximal exercise. Journal of Applied Physiology and Respiratory Environmrntal Exercise Physiology. Aug 1983;55(2):365-367.

100. Hellsten Y, Richter EA, Kiens B, Bangsbo J. AMP deamination and purine exchange in human skeletal muscle during and after intense exercise. Journal of Physiology. Nov 1999;520 Pt 3:909-920. 
101. Robergs RA, Ghiasvand F, Parker D. Biochemistry of exercise-induced metabolic acidosis. American Journal of Physiology Regulatory, Integrative and Comparative Physiology. Sep 2004;287(3):R502-516.

102. Knuttgen HG. Strength training and aerobic exercise: comparison and contrast. $J$ Strength and Conditioning Research. Aug 2007;21(3):973-978.

103. Romero C, Choun J. The Electron Transport Chain. The American Biology Teacher. 2014;76(7):456-458.

104. Cooper L. The Truth About Supplements. Consumer Reports. Yonkers, NY: Consumers Union; 2016.

105. Administration FD. Dietary Supplement Health and Education Act of 1994. 1994; http://www.fda.gov/RegulatoryInformation/Legislation/FederalFoodDrugandCos meticActFDCAct/SignificantAmendmentstotheFDCAct/ ucm148003.htm. Accessed February 25, 2017, 2017.

106. J. NB. Infographics: highlights from the 2013 Supplement Business Report. 2013; http://newhope360.com/supplements/ infographic-highlights-2013-supplementbusiness-report. Accessed February 25, 2017, 2017.

107. Saldanha L. The dietary supplement marketplace. Constantly evolving. Nutrition Today. 2007;42(2):52-54.

108. McDowall J. Supplement use by Young Athletes. Journal of Sports Science and Medicine. 2007;6(3):337-342.

109. Earnest C, Almada A, Mitchell T. Effects of creatine monohydrate ingestion on intermediate duration anaerobic treadmill running to exhaustion. Journal of Strength and Conditioning Research. 1997;11:234-238. 
110. Grindstaff $P$, Kreider R, Bishop R, et al. Effects of creatine supplementation on repetitive sprint performance and body composition in competitive swimmers. International Journal of Sport Nutrition. 1997;7(4):330-346.

111. Burke LM, Pyne DB, Telford RD. Effect of oral creatine supplementation on single-effort sprint performance in elite swimmers. International Journal of Sport Nutrition. Sep 1996;6(3):222-233.

112. Cooke WH, Grandjean PW, Barnes WS. Effect of oral creatine supplementation on power output and fatigue during bicycle ergometry. Journal of Applied Physiology (1985). Feb 1995;78(2):670-673.

113. Febbraio MA, Flanagan TR, Snow RJ, Zhao S, Carey MF. Effect of creatine supplementation on intramuscular $\mathrm{TCr}$, metabolism and performance during intermittent, supramaximal exercise in humans. Acta Physiologica Scandanavia. Dec 1995;155(4):387-395.

114. Mujika I, Chatard J, Lacoste L, Barale F, Geyssant A. Creatine supplementation does not improve sprint performance in competitive swimmers. Medicine and Science in Sports and Exercise. 1996;28:1435-1441.

115. Odland LM, MacDougall JD, Tarnopolsky MA, Elorriaga A, Borgmann A. Effect of oral creatine supplementation on muscle [PCr] and short-term maximum power output. Medicine and Science in Sports and Exercise. Feb 1997;29(2):216-219.

116. Redondo DR, Dowling EA, Graham BL, Almada AL, Williams MH. The effect of oral creatine monohydrate supplementation on running velocity. International Journal of Sport Nutrition. Sep 1996;6(3):213-221. 
117. Snow RJ, McKenna MJ, Selig SE, Kemp J, Stathis CG, Zhao S. Effect of creatine supplementation on sprint exercise performance and muscle metabolism. Journal of Applied Physiology (1985). May 1998;84(5):1667-1673.

118. Vandenberghe $\mathrm{K}$, Goris $\mathrm{M}$, Van Hecke $\mathrm{P}$, Van Leemputte M, Vangerven L, Hespel P. Long-term creatine intake is beneficial to muscle performance during resistance training. Journal of Applied Physiology (1985). Dec 1997;83(6):20552063.

119. Hultman E, Söderlund K, Timmons JA, Cederblad G, Greenhaff PL. Muscle creatine loading in men. Journal of Applied Physiology (1985). Jul $1996 ; 81(1): 232-237$.

120. Juhn MS, Tarnopolsky M. Oral creatine supplementation and athletic performance: a critical review. Clinical Journal of Sports Medicine. Oct $1998 ; 8(4): 286-297$.

121. Andrews R, Greenhaff P, Curtis S, Perry A, Cowley AJ. The effect of dietary creatine supplementation on skeletal muscle metabolism in congestive heart failure. European Heart Journal. Apr 1998;19(4):617-622.

122. Gordon A, Hultman E, Kaijser L, et al. Creatine supplementation in chronic heart failure increases skeletal muscle creatine phosphate and muscle performance. Cardiovasc Research. Sep 1995;30(3):413-418.

123. Poortmans JR, Auquier H, Renaut V, Durussel A, Saugy M, Brisson GR. Effect of short-term creatine supplementation on renal responses in men. European Journal of Applied Physiology and Occupational Physiology. 1997;76(6):566567. 
124. Dash AK, Miller DW, Huai-Yan H, Carnazzo J, Stout JR. Evaluation of creatine transport using Caco-2 monolayers as an in vitro model for intestinal absorption. Journal of pharmaceutical sciences. Oct 2001;90(10):1593-1598.

125. Persky AM, Brazeau GA. Clinical pharmacology of the dietary supplement creatine monohydrate. Pharmacolological Reviews. Jun 2001;53(2):161-176.

126. Karlsson J, Ungell A, Gråsjö J, Artursson P. Paracellular drug transport across intestinal epithelia: influence of charge and induced water flux. European Journal of Pharmacceutical Science. Oct 1999;9(1):47-56.

127. Dash AK, Sawhney A. A simple LC method with UV detection for the analysis of creatine and creatinine and its application to several creatine formulations. Journal of Pharmaceutical and Biomedical Analysis. Jul 2002;29(5):939-945.

128. Reuland E. The Effects of a Single Dosage of Creatine Hydrochloride on Total Training Volume in Resistance Trained Men Versus Women. Bowling Green State University, OH: Master's of Education, Bowling Green State University; 2016.

129. Packer A, Whidden M, Stevens M, Klepfer W, Reed M. The Effects of Creatine Monohydrate and Creatine Hydrochloride Supplementation on Power in Trained Individuals. International Journal of Exercise Science: Conference Proceedings. 2016;9(4):82.

130. Chemical Analysis LS, and Diagnostics. Agilent 1100 Series HPLC Value System User's Guide. 1999; http://www.agilent.com/cs/library/usermanuals/Public/G1380-90000.pdf. Accessed February 4, 2017. 
131. Ware J, Clemens C, Mayhew J, Johnson T. Muscular Endurance Repetitions to Predict Bench Press and Squat Strength in College Football Players. The Journal of Strength \& Conditioning Research. 1995;9(2):99-103.

132. Hoeger W, Hopkins D, Barette S, Hale D. Relationship between repetitions and selected percentages of one repetition maximum: A comparison between untrained and trained males and females. The Journal of Strength \& Conditioning Research. 1990;4(2):47-54.

133. Antonio J, Ciccone V. The effects of pre versus post workout supplementation of creatine monohydrate on body composition and strength. International Society of Sports Nutrition. 2013;10:36.

134. Koenig CA, Benardot D, Cody M, Thompson WR. Comparison of creatine monohydrate and carbohydrate supplementation on repeated jump height performance. Journal of Strength and Conditioning Research. Jul 2008;22(4):1081-1086.

135. Kelly V, Jenkins D. Effect of oral creatine supplementation on near-maximal strength and repeated sets of high-intensity bench press exercise. The Journal of Strength \& Conditioning Research. 1987;12(2):109-115.

136. Bosco C, Tihanyi J, Pucspk J, et al. Effect of oral creatine supplementation on jumping and running performance. International Journal of Sports Medicine. Jul $1997 ; 18(5): 369-372$.

137. Engelhardt M, Neumann G, Berbalk A, Reuter I. Creatine supplementation in endurance sports. Medicine and Science in Sports and Exercise. Jul 1998;30(7):1123-1129. 
APPENDIX A 


\section{Informed Consent Form}

Study Title: Oral Creatine Hydrochloride Supplementation: Acute Effects on Submaximal, Intermittent Bouts of Bench Press and Vertical Jump Exercises

Principal Investigator:

DJ McDonough

Sponsor: N/A
Co-Investigator:

Dr. Shawn Simonson

This consent form will give you the information you will need to understand why this research study is being done and why you are being invited to participate. It will also describe what you will need to do to participate as well as any known risks, inconveniences or discomforts that you may have while participating. We encourage you to ask questions at any time. If you decide to participate, you will be asked to sign this form and it will be a record of your agreement to participate. You will be given a copy of this form to keep.

\section{$>$ PURPOSE AND BACKGROUND}

The purpose of this research is to examine the effects of 1 -week of oral creatine hydrochloride supplementation on three sets of the free weight barbell bench press exercise at $70 \%$ of your 1 repetition maximum and repeated submaximal countermovement vertical jump exercise at $85 \%$ of your maximal vertical jump height. This will provide us with further information about the potential athletic-enhancing effects of supplementing with a newer form of creatine for 1-week. To participate in this study, you must be a non-vegetarian male between the ages of 18 and 34 years, in good physical health (no diagnosed cardiovascular, pulmonary, metabolic, joint, or chronic disease), and have a minimum of 1-year of resistance-training experience and currently resistance-train a minimum of 3-times per week. Further, you must agree to cease the use of all dietary supplements for 3-weeks, during the study.

\section{PROCEDURES}

You will be asked to come to the Boise State University Kinesiology Annex Building on 3 occasions.

\section{Visit 1 - Paperwork, body composition measurement, and familiarization trial (2 hrs) \\ During your first visit, you will complete all paperwork, have your body height and composition (\% body fat, fat free mass, and fat mass) measured, and complete a practice trial of the protocol procedures that will take pace during visits 2 and 3 . Body composition will be measured with a system that measures the amount of air your body takes up within a chamber. This is an egg-shaped structure that uses changes in air pressure and your body size to determine your total body composition breakdown.}

You will be asked to wear a tight-fitting bathing suit or lycra/spandex shorts with a swim cap covering the hair to reduce air blockage. You will enter the system and sit for 
approximately one minute. You will breathe regularly and remain motionless during the testing procedure. A large window is centered in the front of the system so you may see out into the laboratory and may communicate with an investigator if necessary. An emergency release button is located inside the system should you need to terminate the test for any reason.

Next, you will be asked to provide a dietary recall of your typical daily food consumption. This will be used to assess any major dietary changes that may take place during the study. Following, you will be asked to complete practice trials on the free weight bench press and repeated countermovement vertical jumping exercises. This will be identical in nature to the exercise sessions completed during visits 2 and 3. Following, you will be asked to complete testing for your 1 repetition maximum on the free weight bench press exercise, followed by maximal countermovement vertical jump height testing using the Vertec, which is a vertically adjustable height-measuring device. Before leaving, you will be distributed a 1-week (28 grams (fourteen 2 gram packets): 7-days, 4 grams per day) supply of the creatine hydrochloride treatment. You will be asked to take one 1-serving packet ( 2 grams) of the creatine supplement 30 minutes before your resistance training workout and one 1-serving packet ( 2 grams) immediately after your resistance training workout. On days where you do not resistance train (rest-days), you will be asked to take two 2-serving packets (4 grams) in the morning at the same time on every rest-day. Each time you consume the creatine supplement, you will be asked to take it in $300 \mathrm{~mL}$ of semi-cold water, and consume within 5-minutes after mixing.

\section{Visit 2 and 3 - Experimental trials (1.5 hrs)}

During visits 2 and 3 you will assess all body measures in the same fashion as visit 1. Following, you will complete a progressive bench press warmup until working up to your $70 \% 1$ repetition maximum bench press, established during visit 1. Following, you will complete three trials of the bench press at this weight identical to the practice trials during visit 1 . Following, you will complete a low-intensity, 5-minute warmup on the stationary cycle ergometer before completing 3 trials of the repeated vertical jumping test, identical to the practice trial during visit 1 .

\section{RISKS}

The potential risks that may occur with participating in this study include those associated with any exercise. These include muscle/joint soreness, lightheadedness, nausea, and in rare instances, fainting, and heart attack. However, the possibility of serious events happening in people who have no previous history of heart disease is low. The Human Performance Laboratory has a planned response to any emergency procedure and all testing personnel are CPR certified. Consuming high doses of creatine has been associated with some anecdotes of gastrointestinal distress. However, the creatine hydrochloride supplement you will be asked to take will be consumed at a fraction of the dose as typically used in research studies.

\section{BENEFITS}

There will be no direct benefit to you from participating in this study. However, the results of this study may provide information as to which form of commercially available creatine, sold as a dietary supplement, is superior for acute ergogenic benefits. EXTENT OF CONFIDENTIALITY 
Reasonable efforts will be made to keep the personal information in your research record private and confidential. Any identifiable information obtained in connection with this study will remain confidential and will be disclosed only with your permission or as required by law. The members of the research team and the Boise State University Office of Research Compliance (ORC) may access the data. The ORC monitors research studies to protect the rights and welfare of research participants.

Your name will not be used in any written reports or publications which result from this research. Data will be kept for three years (per federal regulations) after the study is complete and then destroyed.

\section{PAYMENT}

You will not be paid for your participation in this study. You will receive 1 free, unopened bottle of creatine upon full completion of the study.

\section{> PARTICIPATION IS VOLUNTARY}

You do not have to be in this study if you do not want to. You may also refuse to answer any questions you do not want to answer. If you volunteer to be in this study, you may withdraw from it at any time without consequences of any kind or loss of benefits to which you are otherwise entitled.

\section{QUESTIONS}

If you have any questions or concerns about your participation in this study, you may contact the Principal Investigator, Daniel McDonough: 650-580-6253 or djmcdonough@u.boisestate.edu.

If you have questions about your rights as a research participant, you may contact the Boise State University Institutional Review Board (IRB), which is concerned with the protection of volunteers in research projects. You may reach the board office between 8:00 AM and 5:00 PM, Monday through Friday, by calling (208) 426-5401 or by writing: Institutional Review Board, Office of Research Compliance, Boise State University, 1910 University Dr., Boise, ID 83725-1138.

\section{DOCUMENTATION OF CONSENT}

I have read this form and decided that I will participate in the project described above. Its general purposes, the particulars of involvement and possible risks have been explained to my satisfaction. I understand I can withdraw at any time.

$\begin{array}{lll}\text { Printed Name of Study } & & \begin{array}{l}\text { Signature of Study } \\ \text { Participant }\end{array} \\ \text { Participant } & \text { Date }\end{array}$


APPENDIX B

Physical Activity Readiness Questionnaire (PAR-Q) 


\section{PAR-Q+}

The Physical Activity Readiness Questionnaire for Everyone

The health benefits of regular physical activity are clear; more people should engage in physical activity every day of the week. Participating in physical activity is very safe for MOST people. This questionnaire will tell you whether it is necessary for you to seek further advice from your doctor OR a qualified exercise professional before becoming more physically active.

\section{GENERAL HEALTH QUESTIONS}

\begin{tabular}{|c|c|c|}
\hline Please read the 7 questions below carefully and answer each one honestly: check YES or NO. & YES & No \\
\hline 1) Has your doctor ever said that you have a heart condition $\square$ or high blood pressure $\square$ ? & $\square$ & \\
\hline $\begin{array}{l}\text { 2) Do you feel pain in your chest at rest, during your daily activities of living, OR when you do } \\
\text { physical activity? }\end{array}$ & ] & \\
\hline $\begin{array}{l}\text { 3) Do you lose balance because of dizziness OR have you lost consciousness in the last } 12 \text { months? } \\
\text { Please answer NO if your dizziness was associated with over-breathing (including during vigorous exercise). }\end{array}$ & ] & ح \\
\hline $\begin{array}{l}\text { 4) Have you ever been diagnosed with another chronic medical condition (other than heart disease } \\
\text { or high blood pressure)? PLEASE LIST CONDITION(S) HERE: }\end{array}$ & 0 & \\
\hline $\begin{array}{l}\text { 5) Are you currently taking prescribed medications for a chronic medical condition? } \\
\text { PLEASE LIST CONDITION(S) AND MEDICATIONS HERE: }\end{array}$ & $\square$ & \\
\hline $\begin{array}{l}\text { 6) Do you currently have (or have had within the past } 12 \text { months) a bone, joint, or soft tissue } \\
\text { (muscle, ligament, or tendon) problem that could be made worse by becoming more physically } \\
\text { active? Please answer NO if you had a problem in the past, but it does not limit your current ability to be physically active. } \\
\text { PLEASE LIST CONDITION(S) HERE: }\end{array}$ & C & \\
\hline 7) Has your doctor ever said that you should only do medically supervised physica & $\square$ & L \\
\hline
\end{tabular}

If you answered NO to all of the questions above, you are cleared for physical activity.

Go to Page 4 to sign the PARTICIPANT DECLARATION. You do not need to complete Pages 2 and 3.

Start becoming much more physically active - start slowly and build up gradually.

Follow International Physical Activity Guidelines for your age (www.who.int/dietphysicalactivity/en/).

You may take part in a health and fitness appraisal.

If you are over the age of $45 \mathrm{yr}$ and NOT accustomed to regular vigorous to maximal effort exercise, consult a qualified exercise professional before engaging in this intensity of exercise.

If you have any further questions, contact a qualified exercise professional.

\section{If you answered YES to one or more of the questions above, COMPLETE PAGES 2 AND 3.}

Delay becoming more active if:

You have a temporary illness such as a cold or fever; it is best to wait until you feel better.

You are pregnant - talk to your health care practitioner, your physician, a qualified exercise professional, and/or complete the ePARmed-X+ at www.eparmedx.com before becoming more physically active.

Your health changes - answer the questions on Pages 2 and 3 of this document and/or talk to your doctor or a qualified exercise professional before continuing with any physical activity program. 


\section{PAR-Q+ \\ FOLLOW-UP QUESTIONS ABOUT YOUR MEDICAL CONDITION(S)}

1. Do you have Arthritis, Osteoporosis, or Back Problems?

If the above condition(s) is/are present, answer questions 1a-1c

If NO $\square$ go to question 2

1a. Do you have difficulty controlling your condition with medications or other physician-prescribed therapies? (Answer NO if you are not currently taking medications or other treatments)

1b. Do you have joint problems causing pain, a recent fracture or fracture caused by osteoporosis or cancer, displaced vertebra (e.g., spondylolisthesis), and/or spondylolysis/pars defect (a crack in the bony ring on the back of the spinal column)? 1c. Have you had steroid injections or taken steroid tablets regularly for more than 3 months?

YES $\square$ NO

2. Do you currently have Cancer of any kind?

If the above condition(s) is/are present, answer questions $2 a-2 b$

If NO $\square$ go to question 3

2a. Does your cancer diagnosis include any of the following types: lung/bronchogenic, multiple myeloma (cancer of plasma cells), head, and/or neck?

2b. Are you currently receiving cancer therapy (such as chemotheraphy or radiotherapy)?

YES $\square$ NO $\square$

YES $\square$ NO

3. Do you have a Heart or Cardiovascular Condition? This includes Coronary Artery Disease, Heart Failure, Diagnosed Abnormality of Heart Rhythm

If the above condition(s) is/are present, answer questions $3 a-3 d$

If No $\square$ go to question 4

3a. Do you have difficulty controlling your condition with medications or other physician-prescribed therapies? (Answer NO if you are not currently taking medications or other treatments)

3b. Do you have an irregular heart beat that requires medical management? (e.g., atrial fibrillation, premature ventricular contraction)

3c. Do you have chronic heart failure? YES NO

3d. $\quad$ Do you have diagnosed coronary artery (cardiovascular) disease and have not participated in regular physical $\quad$ YES $\square$ NO $\square$ activity in the last 2 months?

4. Do you have High Blood Pressure?

If the above condition(s) is/are present, answer questions $4 \mathrm{a}-4 \mathrm{~b}$

If No $\square$ go to question 5

4a. Do you have difficulty controlling your condition with medications or other physician-prescribed therapies? (Answer NO if you are not currently taking medications or other treatments) (Answer YES if you do not know your resting blood pressure)

Do you have any Metabolic Conditions? This includes Type 1 Diabetes, Type 2 Diabetes, Pre-Diabetes

If the above condition(s) is/are present, answer questions $5 \mathrm{a}-5 \mathrm{e}$

If NO $\square$ go to question 6

5a. Do you often have difficulty controlling your blood sugar levels with foods, medications, or other physicianprescribed therapies?

YES $\square$ NO $\square$

5b. Do you often suffer from signs and symptoms of low blood sugar (hypoglycemia) following exercise and/or during activities of daily living? Signs of hypoglycemia may include shakiness, nervousness, unusual irritability, abnormal sweating, dizziness or light-headedness, mental confusion, difficulty speaking, weakness, or sleepiness.

5c. Do you have any signs or symptoms of diabetes complications such as heart or vascular disease and/or complications affecting your eyes, kidneys, OR the sensation in your toes and feet?

YES $\square$ NO $\square$

5d. Do you have other metabolic conditions (such as current pregnancy-related diabetes, chronic kidney disease, or liver problems)?

5e. $\quad$ Are you planning to engage in what for you is unusually high (or vigorous) intensity exercise in the near future? YES $\square$ NO $\square$ 


\section{PAR-Q+}

6. Do you have any Mental Health Problems or Learning Difficulties? This includes Alzheimer's, Dementia, Depression, Anxiety Disorder, Eating Disorder, Psychotic Disorder, Intellectual Disability, Down Syndrome

If the above condition(s) is/are present, answer questions $6 \mathrm{a}-6 \mathrm{~b} \quad$ If No $\square$ go to question 7

6a. Do you have difficulty controlling your condition with medications or other physician-prescribed therapies? YES $\square$ NO $\square$ (Answer NO if you are not currently taking medications or other treatments)

6b. Do you have Down Syndrome AND back problems affecting nerves or muscles?

YES $\square$ NO $\square$

7. Do you have a Respiratory Disease? This includes Chronic Obstructive Pulmonary Disease, Asthma, Pulmonary High Blood Pressure

If the above condition(s) is/are present, answer questions 7a-7d If No $\square$ go to question 8

7a. Do you have difficulty controlling your condition with medications or other physician-prescribed therapies? YES $\square$ No $\square$ (Answer NO if you are not currently taking medications or other treatments) 7b. Has your doctor ever said your blood oxygen level is low at rest or during exercise and/or that you require
supplemental oxygen therapy?

7c. If asthmatic, do you currently have symptoms of chest tightness, wheezing, laboured breathing, consistent cough YES $\square$ No $\square$ (more than 2 days/week), or have you used your rescue medication more than twice in the last week?

7d. Has your doctor ever said you have high blood pressure in the blood vessels of your lungs? YES $\square$ NO

8. Do you have a Spinal Cord Injury? This includes Tetraplegia and Paraplegia If the above condition(s) is/are present, answer questions $8 \mathrm{a}-8 \mathrm{c}$ If No $\square$ go to question 9

8a. Do you have difficulty controlling your condition with medications or other physician-prescribed therapies? (Answer NO if you are not currently taking medications or other treatments)

8b. Do you commonly exhibit low resting blood pressure significant enough to cause dizziness, light-headedness, and/or fainting?

8c. Has your physician indicated that you exhibit sudden bouts of high blood pressure (known as Autonomic Dysreflexia)?

YES $\square$ NO

9.

Have you had a Stroke? This includes Transient Ischemic Attack (TIA) or Cerebrovascular Event If the above condition(s) is/are present, answer questions $9 a-9 c$

If NO $\square$ go to question 10

9a. Do you have difficulty controlling your condition with medications or other physician-prescribed therapies? (Answer NO if you are not currently taking medications or other treatments)

9b. Do you have any impairment in walking or mobility?

9c. Have you experienced a stroke or impairment in nerves or muscles in the past 6 months? YES $\square$ NO

10. Do you have any other medical condition not listed above or do you have two or more medical conditions? If you have other medical conditions, answer questions 10a-10c

If No $\square$ read the Page 4 recommendations

10a. Have you experienced a blackout, fainted, or lost consciousness as a result of a head injury within the last 12 months OR have you had a diagnosed concussion within the last 12 months?

\begin{tabular}{lll}
\hline 10b. $\quad$ Do you have a medical condition that is not listed (such as epilepsy, neurological conditions, kidney problems)? YES $\square$ NO $\square$ \\
\hline 10c. $\quad$ Do you currently live with two or more medical conditions?
\end{tabular} PLEASE LIST YOUR MEDICAL CONDITION(S) AND ANY RELATED MEDICATIONS HERE:

\section{GO to Page 4 for recommendations about your current medical condition(s) and sign the PARTICIPANT DECLARATION.}


APPENDIX C

Institutional Review Board Protocol 
This research was conducted under approval from the Institutional Review Board at Boise State University, protocol \#103-MED-003. 